\section{EL DERECHO A UN AMBIENTE SANO, UN LÍMITE AL EJERCICIO DE LA EXPLOTACIÓN MINERA EN EL CERREJÓN Y LA GUAJIRA, CON REPERCUSIONES EN EL SISTEMA GENERAL DE REGALÍAS. PERIODO 2010- 2015*}

\begin{abstract}
THE RIGHT TO A HEALTHY ENVIRONMENT, A LIMIT TO THE EXERCISE OF THE MINING EXPLOITATION IN CERREJÓN AND GUAJIRA, WITH IMPLICATIONS IN THE GENERAL ROYALTIES SYSTEM. PERIOD 2010 - 2015
\end{abstract}

\author{
O DIREITO A UM AMBIENTE SAUDÁVEL, UM \\ LIMITE DO EXERCÍCIO DA EXPLORAÇÃO DA \\ MINERAÇÃO EM CERREJÓN E LA GUAJIRA, \\ COM IMPLICAÇÕES NO SISTEMA GERAL DE \\ REGALÍAS. PERÍODO 2010-2015
}

\section{RESUMEN}

El presente artículo explora las repercusiones que tiene la protección constitucional del derecho a gozar de un ambiente sano, a partir del ejercicio de las acciones constitucionales frente a la explotación minera del Cerrejón. El análisis es elaborado con base en la jurisprudencia de la Corte Constitucional, la cual en materia de protección al medio ambiente sano en el departamento de la Guajira es limitada, a pesar del evidente desequilibrio natural que amenaza la supervivencia del entorno de esta región del país. Sin embargo, se llega a la conclusión de que las acciones constitucionales presentadas han generado unas repercusiones de carácter legal e impuesto un límite al ejercicio de la actividad minera en el Cerrejón.

\footnotetext{
* Artículo de reflexión, resultado de proyecto de investigación.

a. Abogado de la Facultad de Derecho de la Universidad Colegio Mayor de Cundinamarca. b. Abogado de la Facultad de Derecho de la Universidad Colegio Mayor de Cundinamarca.

c. Abogado y Magíster en Derecho Administrativo de la Universidad Nacional de Colombia, Especialista en Derecho Administrativo de la Universidad Santo Tomás, Máster en Estudios Políticos Aplicados de la Universidad Complutense de Madrid - U. Internacional Menéndez Pelayo y doctorando en Derecho de la Universidad Carlos III de Madrid.
}

Sergio Alexander Salgado Molina ${ }^{a}$ sasalgado@unicolmayor.edu.co Johann Sebastián Medina González jsmedina@unicolmayor.edu.co Jorge Eliecer Morales ${ }^{c}$ jorgeeliecerabogado@gmail.com

Fecha de recepción: 10 de mayo de 2017 Fecha de revisión: 14 de junio de 2017 Fecha de aceptación: 08 de diciembre de 2017
MISIÓN JURÍDICA

Revista de Derecho y Ciencias Sociales

Bogotá, D.C. (Colombia)

Colaboradores Internos Nacionales

Núm. 14 Año 2018

Enero - Junio, pp. 305 - 331

ISSN 1794-600X 


\section{PALABRAS CLAVE}

Cerrejón, Guajira, Regalías, Medio ambiente, Acciones constitucionales, Erario, Estado.

\begin{abstract}
This article explores the impact of the constitutional protection of the right to enjoy a healthy environment, based on the exercise of constitutional actions against the Cerrejón mining operation. The analysis is based on the jurisprudence of the Constitutional Court, which in terms of protection of the environment in the department of La Guajira is limited, despite the obvious natural imbalance that threatens the survival of the environment of this region of the country. However, it is concluded that the constitutional actions presented have generated legal repercussions and imposed a limit on the exercise of mining activity in Cerrejón.
\end{abstract}

\section{KEY WORDS}

Cerrejón, Guajira, Royalty, Environment, Constitutional actions, Treasury, State.

\section{RESUMO}

Este artigo explora as repercussões da proteção constitucional do direito de desfrutar de um ambiente saudável, desde o exercício de ações constitucionais contra a exploração mineira de Cerrejón. A análise baseia-se na jurisprudência do Tribunal Constitucional, que em termos de proteção do ambiente saudável no departamento de La Guajira é limitada, apesar do evidente desequilíbrio natural que ameaça a sobrevivência do meio ambiente desta região do país. No entanto, conclui-se que as ações constitucionais apresentadas geraram repercussões legais e impuseram limites ao exercício da atividade minera em Cerrejón.

\section{PALAVRAS-CHAVE}

Cerrejón, Guajira, Regalías, Medio ambiente, Acciones constitucionales, Erario, Estado.

\section{INTRODUCCIÓN}

A través de la historia la riqueza de recursos minerales de los países americanos ha generado una concurrencia constante de grandes capitales económicos, que orientan sus intereses en la explotación del suelo como fuente de riqueza. Colombia, que encuentra una posición geográfica privilegiada, cuenta con una caudal de recursos minerales que la referencian como un destino de inversión extranjera.

En la década de los setenta el gobierno colombiano dispuso de la concesión para la explotación de carbón en la denominada zona del Cerrejón. Esta mina a cielo abierto se encuentra ubicada en la órbita del río Ranchería en Departamento de La Guajira y limita con la Sierra Nevada de Santa Marta y Venezuela. Durante la vigencia de la Empresa de Carbones de Colombia, S.A., (Carbocol), presentó una división de zonas que en la actualidad se encuentra vigente con la intención que se desarrollen de manera independiente las operaciones mineras. La denominada zona norte, cuenta con una extensión de 38.000 hectáreas, a diferencia del área central que se reduce a una extensión de 10.000 hectáreas. Por otro lado, el sur cuenta con 32.000 hectáreas de terreno disponible para la explotación (Ohara, 1981, p.12).

Esta operación minera desarrollada bajo un marco jurídico legal permite ingresos al Estado a partir del pago de impuestos y regalías, atendiendo a la autorización para la explotación de los recursos minerales, que ejerce hasta la actualidad y que de conformidad con los proyectos se puede extender hasta el 2034.

Concretamente, la zona de explotación carbonífera de El Cerrejón es una formación geológica ubicada en el departamento de la Guajira que data de fines del paleoceno. La formación que da origen a la mina proporciona campos de hulla o carbón. Este hallazgo mineral, representa un importante recurso económico en la actualidad, que impulsa el desarrollo industrial de muchos países del mundo. La producción elevada en la extracción de carbón ha proporcionado por más de treinta años millones de toneladas del mineral a todo el mundo, lo que la posesiona como la mina más grande de Sudamérica y una de las más grandes del mundo. 
Por otro lado, la actividad económica que lucra a las empresas dedicadas a la extracción mineral genera un ingreso para el Estado por concepto de regalías, que se reconocen como las utilidades que se perciben por la autorización de la explotación de los recursos naturales que se encuentran en el suelo y el subsuelo. Se entiende que estas son un "acto de la soberanía del Estado sobre lo que le pertenece" (Hernández, 2010, p.16).

Los ingresos para la nación producto de la explotación en la mina de El Cerrejón, representan un aporte importante al sistema general del regalías, pero atendiendo al impacto ambiental de la explotación y los perjuicios que repercuten en la población, este aporte de regalías presenta variables en los últimos años, lo cual se requiere determinar si ¿los derechos ambientales, son un límite a la actividad económica minera, que a su vez repercute en el sistema general de regalías?, todo en un marco jurídico en donde toma protagonismo las intervenciones jurisprudenciales de la Corte Constitucional.

El sustento jurídico para esta actividad parte del marco jurídico que se enmarca en la Constitución Política de 1991, en donde se introducen conceptos relacionados al suelo y el subsuelo, además de contener un catálogo importante de derechos que orientan el destino de los recursos captados por mercancías, se establece una organización inicial con respecto a las regalías, denominado Fondo Nacional de Regalías (FNR), que posterior a modificaciones de carácter constitucional, se denomina hasta la actualidad como Sistema General de Regalías.

La entrada en vigencia del acto legislativo 05 de 2011, el cual modificó los artículos 360 y 361 de la Constitución Política de 1991, estableció una contraprestación por permitir la explotación de recursos no renovables en el territorio nacional. Estos recursos deben estar dirigidos a la inversión en desarrollo social, económico y ambiental de las entidades territoriales, así como al ahorro para su pasivo pensional, para inversiones físicas en educación, entre otras. El contenido constitucional desarrollado en los artículos señalados de la Carta política, se desarrolla en virtud de la Ley 1530 del 17 de mayo de 2012 "Por la cual se regula la organización y el funcionamiento del Sistema General de Regalías", la cual tiene como regular la administración, ejecución, control, y destinación de los ingresos al Sistema General de Regalías.
Esta norma a su vez se desarrolla por el Decreto 1077 de 2012, en virtud del cual reglamenta parcialmente la Ley 1530 de 2012 en materia presupuestal y se dictan otras disposiciones.

A su vez, la Constitución Política de 1991 desarrolla derechos de carácter colectivo, como el derecho al ambiente sano que ha tomado protagonismo en el escenario jurídico colombiano (Motta, 2010), este derecho parte de la necesidad de un manejo adecuado para que la explotación de recursos que permita la sostenibilidad del entorno, así como la conservación de los ecosistemas. De igual manera, la relación directa con otros derechos, hacen de este un derecho de carácter fundamental y colectivo (Corte Constitucional, Sentencia T-256, 2015), que encuentra amparo constitucional en el artículo 79 de la Carta Política, y que está llamado a la protección por parte de las autoridades y la sociedad en general.

Concretamente, el derecho al ambiente sano, contempla una mediación entre la sociedad y la naturaleza, que está orientado a la imposición de límites a fin de garantizar el respeto por los recursos naturales (Rodríguez \& Páez, 2012, p.31). Estos límites que enmarcan el campo de acción de los intereses económicos producto de la explotación de recursos naturales presentan un conflicto de intereses que libra tensiones en la mayoría de los casos en la jurisdicción constitucional.

La Corte Constitucional colombiana, a través del ejercicio del control de constitucionalidad, que en el caso de derechos colectivos procede de forma excepcional, sostiene que la defensa del medio ambiente sano es un objetivo del Estado social de derecho, que debe garantizar la supervivencia del ser humano y de las generaciones venideras, razón por la cual debe implementar medidas preventivas y de control en el deterioro ambiental a partir de la imposición de sanciones legales que permitan la reparación del entorno (Corte Constitucional, 2015), y como consecuencia dote a la población del goce que le garantiza el medio ambiente sano.

La Corte Constitucional, a su vez, dispone jurisprudencia regulando lo referente a los derechos fundamentales en diferentes sentencias, entre ellas son relevantes la T-046 de 1999 y la SU-442 de 1997, relacionadas con el ejercicio del derecho al medio ambiente sano y la explotación y transporte de la explotación minera en la zona 
perimetral a El Cerrejón, en el departamento de Magdalena. En dichas sentencias se impone una carga a las empresas encargadas de la gestión minera, referente al saneamiento ambiental, así como a la responsabilidad de la explotación con los habitantes que pertenecen a comunidades indígenas, afrodescendientes y tribales.

Es importante destacar que, la defensa del derecho al medio ambiente sano mediante la acción de tutela en contra de la explotación minera del Cerrejón como tal, se destaca en la sentencia T-56/2015 en donde se precisan responsabilidades para ejercer la explotación en el municipio de Patillas en el departamento de la Guajira, la cual será motivo de análisis en el presente trabajo.

El presente escrito tiene como finalidad realizar una aproximación jurídica referente al derecho a un medio ambiente sano, en relación con la actividad minera desempeñada en el Sur de la Guajira, en la mina del Cerrejón, teniendo en cuenta la relevante repercusión en el sistema general de regalías, que responde a la protección constitucional que ofrece el ordenamiento jurídico para este tipo de derechos. Para lo cual, es necesario comprender el funcionamiento del Sistema General de Regalías, con la intención de analizar los ingresos durante los periodos anteriormente señalados, determinando los factores a los que responde el crecimiento o la reducción de los ingresos anuales.

Por otro lado, se analizará el ejercicio a los derechos del medio ambiente que ejerzan los habitantes del sur de la Guajira, que habitan las periferias de la zona de explotación de El Cerrejón, para lo cual se tendrá en cuenta las intervenciones de la Corte Constitucional y El Consejo de Estado, para finalmente contrastar, las variables de los ingresos en regalías con los límites que imponen los tribunales para la explotación minera en la Guajira en el periodo 2010 - 2015.

Como consecuencia del desarrollo sistemático del presente proyecto, el lector evidenciará el funcionamiento del Sistema General de Regalías, así como el desarrollo de las políticas ambientales empleadas por las empresas extractivas de carbón y las medidas de saneamiento implementadas por estas empresas, de igual manera que se encontrará con un análisis de las acciones constitucionales aplicables para el ejercicio de los derechos al medio ambiente sano.

\section{METODOLOGÍA}

La tensión existente entre los derechos económicos de las empresas extractivas de recursos minerales, en contraposición de los derechos al medio ambiente sano que requieren los individuos para desarrollarse dignamente, es una constante en los escenarios jurídicos de todo el mundo, en donde Colombia se involucra profundamente, atendiendo al potencial que posee en recursos minerales.

La presente investigación socio-jurídica, atiende a la relevancia que representa en el sistema jurídico colombiano el contraste de derechos que libran tensiones en la jurisdicción constitucional.

El enfoque de la presente investigación se orienta a establecer una relación con lo cualitativo y lo cuantitativo, es decir, que es de carácter ecléctico, corresponde a la investigación en cifras y estadísticas de índices de exportación y crecimiento de la actividad minera en la zona del Cerrejón, de igual manera, la valoración cualitativa, hace referencia al impacto de las decisiones judiciales que de alguna manera limitan los intereses económicos fruto de la explotación minera de carbón.

Partiendo del análisis normativo y social que se desarrolla a partir de la operación de una de las minas de carbón a cielo abierto más grandes del mundo, denominada El Cerrejón, ubicada en el sur de la Guajira, en contraste con las repercusiones ambientales que causan complicaciones para los lugareños, afectando directamente a las comunidades que habitan la periferia y que a través de mecanismos judiciales exigen los derechos que ampara la Constitución Política, se encauza la presente investigación bajo un carácter socio-jurídico, que se sustenta en conceptos doctrinales y jurisprudenciales.

La metodología de la investigación permite el análisis y la clasificación de forma adecuada, para las fuentes de información producto de la labor investigativa. El método de que se implementa, para la presente investigación es el método deductivo, partiendo del análisis general del que parte la investigación orientada a definir 
los límites a los derechos económicos de la explotación minera en el Cerrejón.

El carácter descriptivo de la investigación posibilita analizar las situaciones que se desarrollan en torno al marco jurídico colombiano que regula, por un lado, el derecho al medio ambiente y, por el otro, el derecho económico que adquieren las empresas mineras que explotan carbón en la Guajira. Esta investigación, además se orienta a dimensionar las repercusiones económicas frente a los ingresos del Sistema general de Regalías.

Como consecuencia del aspecto descriptivo del presente artículo, el análisis documental resulta fundamental, además de la recolección de datos, que es de carácter secundario, ya que la fuente principal es la información contenida en textos, revistas, periódicos, jurisprudencia y páginas web como instrumentos de recolección de datos.

Se espera dimensionar las repercusiones de reducir la explotación minera de carbón, sobre los ingresos a las arcas del Estado, manifestadas en el Sistema General de Regalías. De igual forma destacar la tensión entre los intereses económicos y los derechos al medio ambiente.

\section{LA GUAJIRA Y ÉL CERREJÓN, UNA ZONA DE EXPLOTACIÓN MINERA CON MÁS DE TREINTA AÑNOS}

El Cerrejón es una formación geológica ubicada en el departamento de la Guajira al norte de la geografía colombiana, departamento limita por el norte y el oriente con el Océano Atlántico, al sur con los departamentos del Cesar, de igual forma que con el departamento de Magdalena, para ser más preciso con la Sierra Nevada de Santa marta, y por el oriente con la República Bolivariana de Venezuela (Centro de Investigación y Educación Popular, 2016, p.8).

El yacimiento mineral que data su formación a finales del periodo del paleoceno, se encuentra ubicado en el sur del departamento, y se dividen en tres zonas de explotación, abarcando una extensión de explotación en la zona norte de 38.000 hectáreas, el área central con 10.000 hectáreas y área sur con 32.000 hectáreas, las cuales limitan con el departamento del Cesar, en el cual se extiende la explotación para el interior del departamento
(Ohara, 1981, p.10). La formación que da origen a la mina, proporciona espacios nutridos de hulla que componen la fuente de explotación.

Este hallazgo mineral, representa un importante recurso económico en la actualidad, que impulsa el desarrollo industrial de muchos países del mundo. Con cifras en ventas del 58\% con destino a países europeos, el 9 \% para Estados Unidos, y $12 \%$ repartido en países americanos (Cerrejón, 2017).

La producción elevada en la extracción de carbón ha proporcionado, por más de treinta años, millones de toneladas de carbón a todo el mundo, lo que la posesiona como la mina más grande de Sudamérica y una de las más grandes del mundo con la técnica de explotación a cielo abierto.

En noviembre de 1975, el gobierno colombiano creó la Empresa Industrial y Comercial del Estado, Carbones de Colombia (CARBOCOL), como una empresa adscrita al Ministerio de Minas y Energía, con la premisa de explorar, y disponer de la explotación, para la posterior comercialización de carbón, en la cuenca del rio rancherías en el departamento de la Guajira. Para tal fin, el gobierno colombiano dispuso de una propuesta a 17 empresas con experiencia en la labor minera, para la participación en la licitación para la explotación de 32000 hectáreas en las que abunda el mineral, las cuales componen actualmente la denominada zona de "El Cerrejón zona Norte". Interesadas por la inversión, se presentaron 5 empresas, de las cuales solo 3 cumplieron los requisitos para acceder a la explotación. En diciembre de ese mismo año, la empresa Intercor, filial de Exxon, suscribió el contrato de asociación entre Carbocol e Intercor, cuyo objetivo principal fue desarrollar la minería abierta en gran escala, así como la construcción de canales de transporte para la comercialización del carbón (Ortega, 2016, p.24).

El contrato de asociación suscrito para la explotación de las 32.000 hectáreas disponibles en ese momento se dispuso por un periodo de 33 años para desarrollar los recursos carboníferos del Cerrejón ejecutado en tres etapas (Castro, 2000, p.13). El primer periodo de explotación que correspondió de 1977 a 1980, en donde posterior a una etapa de verificación asertiva, se declaró la comercialidad del Cerrejón por parte 
del Estado colombiano. El documento consolidó las formalidades para la explotación. El segundo periodo de exploración entre 1981 y 1986, y un último periodo de construcción y producción de 1986 a 2009. Es de anotar que, en 1999, se firmó un acuerdo con el Estado colombiano para extender la última etapa por 25 años más, hasta 2034 (Cerrejón, 2017).

La producción de carbón en Colombia, representa la segunda plaza en la exportación del país debajo del petróleo, el aporte principal para la exportación del mineral, corresponde en un $92.3 \%$ del Cerrejón y el restante a carga de la Drummond, que explota la zona de carbonífera en el departamento del Cesar (Sarmiento, 2008, p.17). Las repercusiones económicas, permite la reducción de las actividades de contrabando, y contribuye ampliamente a la generación de empleo, siendo la Guajira y el Cesar los departamentos con menor índice de desempleo en Colombia (El País, 2014).

La construcción de la vía férrea que se extiende a lo largo de 150 kilómetros desde el interior del departamento hasta la costa, hace parte de la operación integrada que se compone de dos aeropuertos privados en la zona de explotación y el puerto (Centro de Investigación y Educación Popular, 2016), evidenciando una inversión que responde a los altos volúmenes de producción de la región, que contrasta abruptamente con las condiciones precarias de la sociedad local.

Atendiendo a la producción elevada que tuvo acogida a inicios del nuevo mileno, las reservas con las que cuenta el Cerrejón, corresponde a dos mil ciento cuarenta millones de toneladas(2140.000.000ton), las cuales se destinan para regular los ingresos en contraposición a la baja la producción (Sarmiento, 2008, p.11).

Con el fin de orientar las practicas al mejoramiento de la calidad de vida de las poblaciones perimetrales en el sector de explotación de la mina, se diseñó la formulación del denominado Plan Integral de Aseguramiento, que hace parte del pacto mundial, principios voluntarios del sector extractivo, la norma interna SA8000 y las disposiciones normativas contempladas en protocolo de Kioto.

\subsection{GESTIÓN AMBIENTAL EN LA PRODUCCIÓN MINERA}

Uno de los aspectos más relevantes en la explotación minera, es el impacto ambiental que genera la extracción del mineral. En El Cerrejón, se destacan las repercusiones en el ambiente en relación con la contaminación de aguas superficiales y subterráneas, emisión de gases y partículas de polvo, así como la rehabilitación de tierras.

La necesidad de la utilización de agua para la extracción de carbón genera un panorama preocupante, teniendo en cuenta que este recurso es vital para la subsistencia del ser humano, y el sustento de la flora y la fauna que se desarrolla en el territorio.

Las fuentes hídricas para la operación minera en El Cerrejón, son clasificadas en fuentes de alta calidad y de baja calidad. El consumo de las fuentes de alta calidad se orienta a la reducción, remplazándolo el consumo de baja calidad. Las empresas explotadoras en la zona del Cerrejón, adoptan medidas de control con el fin de proteger el recurso natural, ofreciendo un constante monitoreo de la pureza del río Ranchería y demás fuentes hídricas afectadas con la explotación, abarcando lo que refiere a las aguas subterráneas del acuífero superficial, y ejerciendo un control detallado de aguas residuales e industriales, con la implementación de lagunas de retención y de estabilización (Báez \& Trujillo, 2014, p.31).

El agua destinada para la extracción mineral es de alta calidad, proviene de fuentes superficiales y subterráneas (Díaz, 2004, p.42), que se almacenan en pozos y sumideros los cuales tienen la misión de recoger las partículas aéreas producto de la explotación minera.

La extracción de hulla genera partículas de polvo que varían según las condiciones climáticas, responden a factores relacionados con la velocidad y dirección del viento, la humedad, la temperatura (Báez \& Trujillo, 2014, p.33). La gestión realizada en el Cerrejón para el manejo de partículas aéreas, parte de la medición de puntos críticos de emisión de partículas, los cuales se centran principalmente en las tareas de acarreo, para ello se implementa el uso de agua industrial compuesta de aditivos químicos que permiten aplacar las emisiones y conducirlas a las permitidas. 
El programa de rehabilitación de tierras afectadas por la minería, es un proyecto impulsado por la intención voluntaria de los administradores de la mina, cumple con los estándares internacionales, con una inversión de setenta millones de dólares, que completan los proyectos de saneamiento relacionados con el agua y el aire, la flora y la fauna (Sarmiento, 2008, p.6).

\subsection{LA POLÍTICA MINERA EN EL PLAN NACIONAL DEL DESARROLLO}

Colombia se ha caracterizado por ser un país que cuenta con una cantidad considerable de minerales, los recursos no renovables del que se encuentran en el territorio, se explotan por intermedio de empresas especializadas en la labor minera que, a su vez, se encuentran enmarcados en los diseños metodológicos proyectados por intermedio del gobierno nacional, a través de proyecciones que definen la política de explotación.

El Plan Nacional de Desarrollo, contenido en la Ley 1753 de 2015, contempla las directrices propuestas por el Gobierno Nacional pro el periodo 2014 - 2018, contemplando una inversión en desarrollo minero-energético con miras a la equidad regional de setenta y ocho mil quinientos tres millones de pesos $(\$$ 78.503.614.000), encontrando una inversión mayor que la destinada para las Tecnologías de la Información y las Comunicaciones (TIC), para el mismo periodo.

Como propuesta fundamental, el Plan Nacional de Desarrollo tiene como objetivo, la formalización de la actividad minera ejercida a pequeña y mediana escala, a partir de la promoción del subcontrato del título minero, en donde los mineros irregulares podrán poseer hasta el 30\% del título minero. De igual forma se permite la devolución de áreas de explotación informal, para la legalización del título minero.

Los términos para las prórrogas de las concesiones mineras deberán otorgarse por un periodo mínimo de dos (2) años, que será evaluado por la autoridad minera, quien podrá extender los títulos hasta por treinta años posteriores a la finalización del periodo otorgado inicialmente. En el periodo de evaluación para la prórroga, podrán negociarse nuevamente las contraprestaciones y los contratos bajo nuevas condiciones, que deben quedar en firme con la prórroga del título minero.

Se dirige una política de protección a los páramos que pretenden ser profanados con la explotación minera, o incluidos en el área de explotación por extensión, teniendo como represarías en contra de las empresas explotadoras, la caducidad de títulos mineros, así como la exclusión en los procesos que participen para la adjudicación de zonas de explotación.

Por otro lado, el Ministerio de Minas y Energía, órgano encargado de desarrollar las políticas de explotación minera contenidas en el Plan Nacional de Desarrollo, mediante la Unidad de Planeación Minero Energética, ha desarrollado un Plan Nacional para el Desarrollo Minero que se extiende en proyección hasta el año 2019.

La tendencia del postulado del Ministerio de Minas y Energía, está orientado a la inclusión de los entes territoriales para la participación en el desarrollo de las políticas, que se basas en la inclusión, control y vigilancia de las empresas encargadas de la explotación minera. Políticas que resultan con más acogida en los departamentos que desarrollan una tradición minera, toda vez que es necesaria la cercanía con los territorios de explotación que se relacionan con sectores de la economía que permiten el impulso de la región (Unidad de Planeación Minero Energética Subdirección de Planeación minera, 2006).

La integración institucional que promueve el gobierno central, a partir de la creación de talleres que tienen como objeto el debate en la articulación de políticas entre la visión del Ministerio de Minas y Energía, y los Planes de Desarrollo territoriales, permite la proyección de la política minera colombiana hasta el año 2019.

Para la implementación de políticas, el Estado deberá obedecer a determinados criterios que fomentan la actividad minera de manera sana y legal, criterios que se construyen a partir de las observaciones de las empresas mineras auspiciadas por los entes territoriales.

En primer lugar, el Estado deberá eliminar las ambigüedades que permiten crear desconfianza para la inversión minera, y que debilitan la credibilidad en las instituciones, teniendo una repercusión la inversión extranjera. De igual forma, las normas jurídicas que recaigan sobre la explotación minera 
deben estar orientadas al incentivo de la inversión que se afianza con la exposición del potencial minero del país. En tercer lugar, se deberá intervenir la inversión social y ambiental, para las poblaciones que habitan en cercanías a las zonas de explotación, quienes son los primeros en recibir el impacto de la explotación (Unidad de Planeación Minero Energética - Subdirección de Planeación minera, 2006).

De igual manera, el gobierno nacional, presenta peticiones que enfocan las políticas mineras a los intereses de las comunidades en zona de explotación, mediante el cumplimiento de criterios que garanticen una contraprestación razonable.

En primer lugar, se solicita la formalización de la actividad minera con el objetivo de establecer una industria sólida, con aplicación directa de las normas ambientales y de seguridad industrial para el capital humano que soporta la operación. La educación orientada a la comprensión de los beneficios de la actividad minera para la sociedad de la región, contemplada desde aspectos de empleo, sostenibilidad ambiental e inversión económica. Por último, hace un llamado a la inversión bancaria nacional, a fin de apoyar el desarrollo del minero a mediana y pequeña escala (Unidad de Planeación Minero Energética Subdirección de Planeación minera, 2006).

Las empresas extractoras deberán presentar inversión interna encaminada al bienestar social de los empleados y su profesionalización, en pro de aumentar la competitividad sin amenazar la estabilidad de sus trabajadores. Esta inversión interna, deberá estar orientada también, al desarrollo tecnológico que reduzca el daño ambiental y fomente técnicas de extracción más limpias. Por último, se solicita la participación en la promoción de la actividad minera, por intermedio de la participación activa que le acerque al gremio extractor.

\subsection{LA PRODUCCIÓN MINERA Y LA RELACIÓN CON LA GENERACIÓN DE EMPLEO}

Los índices bajos de desempleo, a través del aporte de la mano obrera logra impulsar sectores diferentes de la economía.

El crecimiento económico de la industria minera en la década de los noventa se presentó lento en relación con el crecimiento obtenido en la primera década del nuevo milenio, teniendo en cuenta que se ampliaron las licencias de explotación minera, así como las zonas de explotación ya bajo licencia, aportando al PIB del país en 2003 en 45.5 a 67.4 miles de millones de pesos constantes de 2004 (Cárdenas \& Reina, 2008, 2008, p.31).

El crecimiento de la producción minera, entre el periodo 2001 al 2004, permitió notable participación en cuanto a los índices de desempleo en el departamento en lo que respecta al mismo periodo, logrando un crecimiento que tiene un registro inicial de ciento veinte mil (120.000) empleos, y uno final de ciento ochenta mil (180.000) empleos (Cárdenas \& Reina, 2008, p.31).

En el año 2014, la Guajira registra un desempleo representativo del 6.1 sobre la población del departamento, registrando los indicadores de ocupación más altos en la región caribe durante el último periodo. Sin embargo, tras el análisis del mercado laboral correspondiente al periodo del último trimestre del año 2015, es decir, los meses de octubre, noviembre y diciembre, se evidencia que la oferta laboral en la capital de departamento de la Guajira, (medida por la tasa global de participación) fue de 65,2\% y la tasa de desempleo fue 10,4 generando una tasa de ocupación del 58,4\% (Cámara de Comercio de la Guajira, 2015).

\subsection{LAS REGALÍAS PRODUCTO DE LA EXPLOTACIÓN MINERA DE CARBÓN}

Las regalías son las utilidades que recibe el Estado como contraprestación para permitir la explotación de los recursos que se encuentran en el suelo y el subsuelo, que además no son renovables. Atendiendo a la titularidad en cabeza del gobierno, se entiende que estas, son un acto de la soberanía del Estado sobre lo que le pertenece (Hernández, 2010, p.17).

Los ingresos por regalías que recibe el Estado colombiano producto de la explotación de carbón son un ingreso importante para el erario, en donde la mina del Cerrejón tiene un papel relevante.

Entre 1982 y 1992, los ingresos producto del Carbón correspondieron a más de 67.646 millones de pesos, los cuales se destinan principalmente a fomentar el progreso y el aumento de la calidad de vida de las personas. En 2012 ingresos públicos en regalías, registra un aproximado a cinco mil 
ochocientos millones de pesos, que en 2013 correspondieron a cuatro mil doscientos millones de pesos, que aumentarían en trescientos mil para el 2014 (Fuentes \& Delgado, 2016, p.16).

Con un marco jurídico que emana de la Constitución Política de 1991, en donde se introducen conceptos relacionados al suelo y el subsuelo, además de contener un catálogo importante de derechos que orientan el destino de los recursos captados por mercancías, se establece una organización inicial con respecto a las regalías, denominado Fondo Nacional de Regalías (FNR), que posterior a modificaciones de carácter constitucional, se denomina hasta la actualidad como Sistema General de Regalías.

La entrada en vigencia del Acto Legislativo 05 de 2011, el cual modificó los artículos 360 y 361 de la Constitución Política de 1991, estableció una contraprestación por permitir la explotación de recursos no renovables en el territorio nacional. Estos recursos deben estar dirigidos a la inversión en desarrollo social, económico y ambiental de las entidades territoriales, así como al ahorro para su pasivo pensional $y$ para inversiones físicas en educación, entre otras. El contenido constitucional implícito en los artículos señalados de la Carta Política, se desarrolla en virtud de la Ley 1530 del 17 de mayo de 2012, la cual tiene como fin regular la administración, ejecución, control, y destinación de los ingresos al Sistema General de Regalías.

\subsection{EVOLUCIÓN HISTÓRICA DE LAS REGALÍAS EN COLOMBIA}

Los primeros antecedentes que relacionan la explotación de recursos minerales con beneficios económicos percibidos por el Estado, remiten a la expedición de la ley colombiana sobre minas expedida en 1828, en virtud de la cual, el Presidente de la República, gozaba de facultades para ceder en arriendo las minas que eran propiedad de la nación (Velez \& Uribe, 1890, p.26). Es decir que las regalías en sentido formal no existían, pero en sentido material generaban el vínculo entre explotación minera y recursos para el Estado.

En 1829, se expide la primera norma de regulación minera en el país, sancionada por el entonces presidente Simón Bolívar. Dicha regulación reafirmaba la propiedad de las minas en cabeza de la nación, así como la facultad del gobierno para otorgarla a los particulares que presenten la solicitud (Rettberg, Ortiz, \& Yañez, 2014, p.27).

En 1836, se establece la incorporación a las rentas percibidas por los entes territoriales, de las contribuciones fiscales de los adquirientes de títulos mineros (Gonzalez, 2014, p.37), manifestando un esbozo de las características del sistema nacional de regalías establecido la constitución de 1991, en donde el indicado para la recepción de las regalías era el municipio en donde se ubica la mina o el puerto que se presta para la extracción del recurso.

En 1847, se expidió una ley relacionada con el arrendamiento de las minas de esmeraldas, la explotación de dichas minas solo podría autorizarse por el Estado y debería hacerse en benéfico de este, siempre y cuando no se hubiera regulado la adjudicación por normas anteriores, por lo cual existió una mixtura en la propiedad de las minas de esmeralda, siendo unas propiedades del Estado y otras de carácter privado (Velez \& Uribe, 1890, p.8).

En la Constitución Federal de 1863 de los Estados Unidos de Colombia, se hacer referencia a la propiedad los Estados de la Unión, con respecto a los bienes y las minas que se encontraban en los territorios que, bajo el imperio de la Constitución de 1886, retornaría la propiedad de las minas y las salinas bajo la administración del gGobierno Central (Benitez, 2013, p.42).

Con la Ley 30 de 1903, se estableció un control para las concesiones de explotación de las minas de carbón y petróleo, en virtud del cual requería de la autorización del Congreso para la adjudicación, acto que no tendría relevancia, teniendo en cuenta las facultades del poder ejecutivo para la expedición de normas aplicables sobre la materia (Tapias, 2012, p.37).

Por un largo periodo la explotación de recursos obedecía a la disposición de capital para la inversión, atendiendo a la débil legislación minera, que se orientó al beneficio particular de un grupo selecto que ejercía la explotación a título privado.

En 1905, se inician las primeras adjudicaciones para la explotación de recursos petroleros, bajo una notable ausencia normativa, que se manifestó durante más de medio siglo, hasta la expedición 
de la Ley 20 de 1969, la cual tenía como objeto regular las situaciones de derecho que resultaran inmersas en el otorgamiento de títulos para la explotación minera. Como fundamento principal, la Ley 20, decretaba la extinción de derechos en cabeza de particulares, con respecto a minas adquiridas por cualquier medio legal, anterior a la vigencia de la norma (Aramburo, 1984, p.13).

La existencia formal de las regalías se le atribuye principalmente a la Constitución Política de 1991, contenida en los artículos 360 y 361, en donde se destinó de manera organizada los recursos que percibe la nación producto de la explotación de recursos no renovables.

Con la expedición de la Ley 141 de 1994, se creó el Fondo Nacional de Regalías, así como la Comisión Nacional de Regalías, que se suprimió y liquidó en virtud del decreto 149 de 2004. Dicha comisión tenía como función, verificar la utilización adecuada de los recursos productos de las regalías y las compensaciones, percibidas por el Fondo Nacional de Regalías (Torres, 2008, p.11).

El marco jurídico que compone el actual Sistema General de Regalías, parte de la entrada en vigencia del Acto Legislativo 05 de 2011, que modificó los artículos 360 y 361 de la Constitución Política de 1991, estableciendo una contraprestación por permitir la explotación de recursos no renovables en el territorio nacional. Estos recursos deben estar dirigidos a la inversión en desarrollo social, económico y ambiental de las entidades territoriales, así como al ahorro para su pasivo pensional; para inversiones físicas en educación, entre otras. El contenido constitucional implícito en los artículos señalados de la Carta Política se desarrolla en virtud de la Ley 1530 del 17 de mayo de 2012, la cual tiene como fin regular la administración, ejecución, control, y destinación de los ingresos al Sistema general de Regalías.

\subsection{EL SISTEMA NACIONAL DE REGALÍAS}

El Sistema Nacional de Regalías es un sistema creado con la Constitución Política de 1991, que fue regido por la Comisión Nacional de Regalías, hasta la entrada en vigencia de la Ley 141 de 1994. Fue establecido con el fin de organizar los recursos que recibe el Estado y destinarlos adecuadamente para su aprovechamiento, en pro del desarrollo de los gobernados. Sin embargo, el sistema establecido por la Ley 141, fue modificado por el Acto Legislativo 02 de 2005, que estableció el Sistema General de Regalías vigente, obligando a la liquidación del sistema establecido por la norma de normas.

Se entiende que las regalías son la contraprestación que recibe el Estado por permitir la explotación de los recursos no renovables que se encuentran en el territorio nacional (Hernández, 2010). Bajo este Sistema Nacional, se encuentra una clasificación de las regalías en regalías directas, regalías indirectas y compensaciones (Torres, 2008, p.54).

Las regalías directas son aquellas que percibían los entes territoriales, los puertos fluviales y marítimos, involucrados con el proceso de explotación del mineral que estuviesen destinados a dieciocho de los treinta y dos departamentos que componen el territorio colombiano (Ortega, 2016, p.34).

Las regalías indirectas son aquellas que son producto del remanente de regalías, que se distribuyen entre los entes territoriales, y que son conducidas al fondo del sistema nacional, para ser administradas por Planeación Nacional (Torres, 2008).

Las compensaciones se presentan como un ingreso adicional a las regalías, producto de una contraprestación, en la cual las compañías extractoras pagan por el posible daño ambiental o cultural realizado por la operación minera (Córdoba, 2009, p.28).

El sistema general de regalías, se compone a partir de la centralización de las regalías no asignadas a los municipios productores o portuarios por ministerio de la ley les pertenecen a los entes territoriales, pero se encuentran bajo la administración de la Dirección General del Tesoro Nacional del Ministerio de Hacienda y Crédito Público (Torres, 2008, p.56). Sin embargo, la Corte Constitucional ha sostenido, que las regalías no pertenecen a los municipios, toda vez que al tenor de lo señalado en los artículos 360 y 361 de la Constitución Política, solo se les atribuye una participación sobre las regalías, en donde les corresponde en gran parte por ministerio de la Ley (Corte Constitucional, 2003).

La conformación del Sistema General de Regalías, de conformidad con la Ley 141 de1994, 
se sustenta en un fondo que con base en los remanentes de la asignación de regalías a los municipios. Se integraba a partir de diferentes cuentas correspondientes a cada territorio de donde provenían, se destinaban para invertir en el desarrollo minero, así como en la promoción del desarrollo en infraestructura de la región.

Entre 1994 y 2009, el fondo nacional de regalías, disponía del 15\% del capital recaudado para desarrollo e inversión en materia energética para cada región, quienes previos a disponer de los recursos, estaban sujetos a la inclusión de los proyectos en el Plan de Desarrollo regional, así como al sustento de los mismos, mediante la presentación del proyecto (Fuentes, 2013, p.45).

Posterior a la división de los recursos, que obedecen a la participación de las regiones en la proposición de proyectos de infraestructura energética, el remanente que se encontraba en el Fondo Nacional de Regalías, se destinaba para la reinversión en minería en un porcentaje igual al 20\%, el resarcimiento de los daños ambientales producto de la explotación de recursos en el suelo y subsuelo en porcentaje igual al 20\%. El 59\% restante debía destinarse a la inversión en infraestructura en proyectos prioritarios en los que los municipios formularan propuestas de inversión.

El valor correspondiente al desarrollo minero se invertía en el desarrollo de técnicas y estudios de minería, para la explotación eficiente, enfocando el desarrollo minero a pequeña escala y mediana escala, en los cuales se repartían el 30\% para el desarrollo minero de piedras preciosas y metales, y el 70\% para el desarrollo de la minería de Carbón. Entre 1994 y 1999 , el $0.5 \%$ de los recursos destinados al fomento de la minería a pequeña y mediana de carbón, sirvieron para la inversión en maya vial en las zonas de extracción del mineral en los departamentos de Boyacá y Cundinamarca.

En referencia a los recursos destinados a mitigar el impacto ambiental de la extracción minera, el 15\% deberán estar destinados a la Amazonía, Chocó y el Archipiélago de San Andrés, Providencia y Santa Catalina, así como a los territorios periféricos a las zonas de explotación en donde habiten Comunidades Indígenas que se afecten directa o indirectamente. (Rudas, 2014, p.47).
Sin embargo, este sistema fue suprimido a partir del primero de enero de 2012, atendiendo a lo previsto en el parágrafo 1 transitorio del artículo 2, contenidos en el Acto Legislativo 05 de 2011 y el artículo 129 del Decreto 4923 de 2011, y la Ley 1530 de 2012.

\subsubsection{La Comisión Nacional de Regalías}

Creada en virtud de la Ley 141 de 1994 y suprimida atendiendo al Decreto 149 de 2004, la Comisión Nacional de Regalías, era una Unidad Administrativa Especial, sin personería jurídica, que se manifestaba por intermedio de un órgano de carácter colegiado, que se encargaba de la administración de Fondo nacional de regalías, mediante la emisión de decisiones que determinaban el destino de las regalías (Hernández, 2010, p.34).

Como órgano colegiado, estaba presidido por el Director Nacional de Planeación, que adquirió esta condición posterior a la cesión de la presidencia por parte del Ministro de Minas y Energía, situación que serviría para ejercer el mismo puesto, en el Fondo Nacional de Regalías. Este cuerpo colegiado revestido de facultades para adoptar decisiones, se componía de diversos integrantes entre los cuales se destacaban, el Ministro de Minas y Energía o en su defecto el viceministro, el Director Nacional de Planeación o el Subdirector General de Planeación, El jefe del departamento Nacional de Planeación o el subjefe, el representante a nivel nacional del ente encargado de dirigir las políticas de medio ambiente, el Ministro de Transporte o su Viceministro, los gobernadores de departamento que integran los Conpes, entre los cuales tres (3) debían pertenecer a departamentos sin zonas de explotación y dos (2) provenientes de departamentos productores. Un alcalde de los municipios portuarios en donde se centre las actividades producto de la extracción de recursos y el alcalde del Distrito Capital de Bogotá (Torres, 2008, p.46)

Las funciones de la Comisión Nacional de Regalías, se relacionan con la vigilancia y el control de las regalías directas e indirectas, sin embargo con la expedición del Decreto 2141 de 1999, se atribuyeron más de 27 funciones dentro de las cuales se destacan, la aprobación del proyecto de presupuesto anual del Fondo Nacional de Regalías, la evaluación de los informes de gestión y seguimiento presentados por el Director General y la aprobación del proyecto presupuestal 
de la Comisión Nacional de Regalías, entre otras (Hernández, 2010, p.4).

Con la expedición del Decreto 149 de 2004, se ordenó la supresión y liquidación de la Comisión Nacional de Regalías que, a partir de la vigencia de la referenciada norma, se extendió el plazo de un año para el cumplimiento de lo ordenado.

Atendiendo a la experiencia acumulada y la necesidad de gestionar la finalización de los proyectos que se desarrollaron en vigencia del Fondo Nacional de Regalías, se designó al Departamento Nacional de Planeación, quien diseñó la estrategia para el manejo administrativo y de los recursos.

Para determinar el cumplimiento de lo ordenado, creo la subdirección de regalías, que funcionó posteriormente como una División (Torres, 2008, p.57).

Las competencias más destacadas, delegadas a Departamento Nacional de Planeación, de conformidad con el artículo 4 del Decreto 149 de 2004 eran las siguientes:

- Responder por la guarda y administración de los bienes y haberes que se encuentren en cabeza del organismo en liquidación. Ejecutar los actos que tiendan a facilitar la preparación y realización de una liquidación rápida y efectiva.

- Elaborar el anteproyecto de presupuesto del organismo en liquidación, para su aprobación y trámite correspondiente.

- Presentar el informe final general de las actividades realizadas en el ejercicio de su encargo.

- Rendir informes mensuales de su gestión y los demás que se le soliciten.

\section{DEPARTAMENTO NACIONAL DE PLANEACIÓN EN RELACIÓN CON LAS REGALÍAS}

Atendiendo a las funciones delegadas por la supresión de la Comisión Nacional de Regalías, el Departamento Nacional de Planeación, cumpliría funciones relacionadas con el registro de los proyectos viables de conformidad con la información suministrada por los ministerios, determinado la prioridad para el desarrollo. De igual manera, ejerce labor directa de vigilancia a los recursos de las regalías y compensaciones, por sus propios medios o por intermedio de interventores, además de estar revestido de autoridad, para adoptar las medidas preventivas y correctivas que dirijan el destino de los recursos (Dirección de Regalías, 2007).

A cargo del director del Departamento Nacional de Planeación, se encuentra la representación legal del Fondo Nacional de Regalías, así como la proyección de las políticas en materia de regalías y su ejecución con el objetivo de asegurar la inversión que destina la norma constitucional. Otras funciones necesarias que destacan la relevancia del DNP en relación con las regalías, es la libertad de contratación para componer el equipo administrativo necesario para cumplir con la labor misional, contratación de interventorías para la adecuada vigilancia de los proyectos encargados de ejecutar principalmente por los entes territoriales.

La vigilancia sobre las regalías es ejercida mediante las inspecciones realizadas a las entidades territoriales que se encuentran desarrollando proyectos financiados con dinero de las regalías y las compensaciones, en donde se observa la ejecución de conformidad con lo aprobado por parte de una Comisión de visitas, quien requerirá la información necesaria a la autoridad regional que presentó el proyecto. En caso de presentarse alguna irregularidad, la comisión deberá realizar un informe en donde se relacionen las incongruencias, y lo presentará ante el Director Nacional de Planeación, encargado de adoptar medidas correctivas de conformidad con la Ley, con el fin de que se supere el impase y se logre la ejecución del proyecto (Torres, 2008, p.55).

El sistema de información de regalías, es un registro histórico que permite evidenciar los desembolsos, inversiones y actividades relacionadas con las regalías, funcionalmente se le atribuyó a la presidencia de la Comisión Nacional de Regalías, pero una vez se realizó la supresión, se le delegó al director del DNP, quien mediante las competencias designadas por el decreto $195 \mathrm{de}$ 2004 cumple más de treinta y cinco (35) funciones, dentro de las cuales se destacan, administrar el 
registro de los proyectos declarados viables, para ser financiados con recursos del Fondo Nacional de Regalías, coordinar con el objetivo de cumplir las políticas de inversión pública diseñadas para el Fondo Nacional de Regalías, entre otras.

\subsection{SISTEMA GENERAL DE REGALÍAS}

El actual Sistema General de Regalías colombiano, se conformó a partir de la expedición del Acto Legislativo 05 de 2011, en virtud de cual se modificaron los artículos 360 y 361 de la Constitución Política de 1991. Es de anotar que, los recursos que percibe la nación no integran el Presupuesto General de la Nación ni el Sistema General de Particiones (Departamento Nacional de Planeación, 2011)

Con respecto al nuevo artículo 360, se rescata el concepto de "regalía", entendida como una contraprestación por la explotación de recursos no renovables en el suelo y el subsuelo (Torres, 2008). Se introduce la facultad del legislativo, para promulgar la Ley que se encargue de establecer los términos en que se desarrollaran las regalías (Puentes, 2013, p.61), es decir la regulación, la organización y el funcionamiento del Sistema General de Regalías. Dicha ley determina la distribución, los objetivos, los fines, la administración, la ejecución, el control, el uso eficiente y la destinación de los ingresos provenientes de la explotación de los recursos naturales no renovables precisando las condiciones de participación de sus beneficiarios (Puentes, 2013, p.62)

El artículo 361 de la Carta política colombiana, que se encontraba limitado antes de la reforma, solo contenía unos principios básicos, sobre los cuales el Congreso de la República desarrollaría la norma reguladora del Sistema General de Regalías. El nuevo texto constitucional contenido en el Acto Legislativo 05 de 2011, se encargó de introducir las minucias necesarias para nutrir el ahora denominado Sistema General de Regalías. Una de las principales novedades con el artículo en cuestión, es la determinación del alcance de las regalías, las cuales deberían implementarse para el desarrollo económico, ambiental y social de las entidades territoriales en donde se encuentran ubicadas las zonas de explotación.

Este nuevo marco normativo para las regalías abarca temas para el destino como el ahorro para financiar el pasivo pensional, el ahorro público, para la fiscalización, exploración y explotación de yacimientos, para intervención del Estado que garantice condiciones de igualdad, entre otras. Se otorgó una flexibilidad en el uso de las regalías, para extender una autonomía a las entidades territoriales con derecho a regalías, con la condición de componer órganos colegiados que tengan como función, la decisión sobre el destino de los recursos (Puentes, 2013, p.63).

De conformidad con el esquema de decisión dispuesto para la descentralización en la vigilancia de los proyectos a nivel regional, son órganos colegiados, los cuales tendrán una composición de un representante de la Comisión Consultiva de Alto Nivel para Comunidades afrodescendientes, un representante de las comunidades indígenas de la región, en calidad de invitado permanente con participación en debates y poder de decisión (Puentes, 2013, p.63).

Los alcances teleológicos de la reforma, obedecen principalmente a la necesidad de hacer extensivos principios constitucionales que se limitaban con la norma anterior, en cuanto a la distribución equitativa de los recursos de la nación. Se orientó igualmente a programar un sistema de ahorro que permita fortalecer la economía nacional (Bonet \& Urrego, 2014, p.43).

La distribución del nuevo Sistema General de Regalías, obedece a su composición, que presenta una concurrencia de diversos fondos los cuales son:

- Fondo de Ahorro y Estabilización

- Fondo de Ahorro Pensional Territorial

- Fondo de Participación de las entidades territoriales receptoras

- Fondo de Compensación Regional

- Fondo de Compensación Regional

- Fondo de Ciencia, Tecnología e Innovación

El fondo de ahorro y estabilización es el encargado de mitigar las variables económicas que se presenta en el desarrollo temporal de la actividad minera (Departamento Nacional de Planeación, 2011), es decir que se diseñó como una herramienta que reduce el flujo de las regalías en época de bonanza, de igual manera que las presenta en amplitud en situaciones en donde el ingreso es bajo. 
Este fondo es producto del conocimiento empírico del manejo de las regalías que acumula el institucionalismo colombiano, en los más de 24 años de la formalización de las regalías con la Constitución Política de 1991, aunado a las variables de riesgo que presenta la economía colombiana, dependiente de la economía mundial. Razón por la cual, para la administración del fondo de ahorro y estabilización, se designó al Banco de la República quien, con experticia en inversión internacional, y manejo de reservas internacionales, asegura la gestión idónea del fondo (Puentes, 2013, p.44).

El fondo de Ahorro Pensional Territorial es un fondo que se alimenta del $10 \%$ del total anual a ser distribuido por el Sistema General de Regalías, está destinado a soportar la cobertura en materia pensional a cargo de las entidades territoriales. La propuesta es acorde con las políticas nacionales y regionales que promueven el ahorro pensional a través de Fondo de Ahorro Pensional Territorial (FONPET).

El fondo de participación de las entidades territoriales receptoras, es un fondo perteneciente al SGR, del que solo disponen las entidades departamentales, distritales y municipales, que cuenten con un sector de explotación de recursos no renovables dentro de sus territorios, de igual manera que los puertos marítimos y fluviales que se relacionen con esa actividad explotadora. Este fondo, permite, mantener la recepción preferente de las autoridades regionales que adicional a la recepción de regalías directas se incluyen en este fondo (Rudas, 2014, p.2).

El Fondo de Desarrollo Regional, es un fondo en virtud del cual, las entidades de todo el país pueden acceder a los recursos del Sistema General de Regalías. Como promotor de la equidad, permite a los municipios participar en la partición de las regalías que percibe el país, a partir de la presentación de proyectos que se orienten al desarrollo de la región. La aprobación de proyectos para el financiamiento se hace de conformidad a las decisiones de órganos colegiados, que compondrán alcaldes, gobernadores y representantes del Gobierno Nacional, quienes mediante la evaluación de criterios de pobreza, población y desempleo, determinarán la viabilidad de los recursos (Departamento Nacional de Planeación, 2011).
El fondo de compensación regional es un fondo de carácter temporal, que se rige bajo los mismos criterios del Fondo de Desarrollo Regional, se destina a la promoción de la equidad en las zonas de frontera, en donde las comunidades en condiciones de desigualdad, se manifiesta en un margen amplio en relación con la población general. (Departamento Nacional de Planeación, 2011). La temporalidad de este fondo, obedece al término de treinta (30) años, tiempo que se estima viable, para que el dinero proveniente de las regalías, permita compensar la desigualdad de las periferias en la frontera. Una vez concluido el tiempo dispuesto por el legislador, los recursos que se destinaban para este fondo se destinarán al Fondo de Desarrollo Regional (Departamento Nacional de Planeación, 2011).

El Fondo de Ciencia, Tecnología e Innovación, encaminado a profesar condiciones de igualdad, recauda el mismo porcentaje dispuesto para el Fondo de ahorro Pensional territorial, con el fin de fomentar el desarrollo científico y tecnológico del país.

\subsection{CONFORMACIÓN DEL SISTEMA GENERAL DE REGALÍAS}

La dirección del sistema General de Regalías, se ejerce por intermedio de la gestión de diversas entidades del Estado, que se desarrollan principalmente por intermedio de la Comisión Rectora, seguida del Ministerio de Hacienda y Crédito Público, el Departamento Nacional de Planeación y el Ministerio de Minas y Energía, todos aunando esfuerzos con la participación de entidades adscritas a cada sector.

La Comisión Rectora, es el órgano principal del SGR, encargado de establecer las políticas de gestión y ejecución de los recursos, mediante la expedición de actos administrativos que aseguren sus postulados. Se compone a su vez, de manera similar a la extinta CNR.

Como un órgano colegiado, se encuentra presidido por el director de Departamento Nacional Planeación y secundada por los ministros de Minas y Energía, así como por el Ministro de Hacienda y Crédito Público, un gobernador representante de los departamentos productores, quien representará los intereses de este grupo un gobernador que será elegido por la Asamblea de Gobernadores ambos serán 
elegidos por el término de un año. Dos alcaldes se suman en representación, quienes se eligen en las mismas condiciones que los gobernadores. Por último, con la calidad de invitados permanentes, se presentarán un Senador y un Representante a la Cámara, elegidos en la comisión quinta de cada cámara, por el periodo de un año. Estos invitados permanentes no tienen participación en las decisiones que se adopten, pero podrán aportar ideas en los temas que sean motivo de análisis (Puentes, 2013, p.37).

\subsection{REGALÍAS DE LA MINERÍA DE CARBÓN}

En vigencia del SGR establecido por la Constitución Política de 1991, las regalías provenientes del carbón, se centran principalmente den la zona norte de Colombia, entre los departamentos de Cesar con un aporte del (37.56\%), La Guajira (34.15\%), Magdalena $(4.95 \%)$, Cundinamarca $(0.51 \%)$ y Atlántico (0.26\%) (Cárdenas \& Reina, 2008, p.23), teniendo participación en la partición de regalías por este concepto, entidades como Ingeominas, las Corporaciones Regionales Autónomas, destacadas entre otras.

En el departamento de la Guajira,
se registraron ingresos en regalías de
$(\$ 729.071 ’ 525.013)$ millones de pesos entre
2004 y 2011 (Rudas, 2014, p.34), siendo una de
las zonas de explotación minera que representa
más ingresos en regalías. Sin embargo, existen
incongruencias en relación con los índices de
pobreza que presenta la región y la deficiente
inversión del fondo general de regalías.

Bajo el nuevo marco normativo del Sistema General de Regalías, los ingresos producto de la explotación de carbón, de conformidad con proyecciones para el periodo 2010 - 2020, permiten evidenciar un incremento en los ingresos que se reflejan en un promedio de aumento anual de cien mil millones de pesos anuales (Rudas, 2014, p.34).

A partir de la vigencia de las regalías bajo el marco jurídico de la constitución política de 1991, las regalías netas de la extracción minera presentaron un crecimiento de 0.1 billones de pesos a 1.7 billones de pesos en 2013, con un crecimiento anual del $16.9 \%$, representando una fuente de ingresos importantes para el Sistema General de Regalías (Escobar \& Martinez, 2014, p.22).

Los ingresos en Regalías del sector minero, en 2011, reportaban el $80 \%$ producto de la explotación del carbón, por encima de la extracción de níquel y oro (Escobar \& Martinez, 2014 , p.22), que a partir del 2011 ha generado un crecimiento anual, aportando ingresos por más de cien mil millones de pesos al SGR (Rudas, 2014, p.34).

Es importante resaltar, que el crecimiento elevado de las regalías provenientes del carbón, no responden en parte al aumento de la producción minera, teniendo en cuenta que la demanda energética, ha posesionado los precios del carbón, así como el aumento de la comercialización. Esta situación resulta prevista bajo el actual Sistema General de Regalías, a partir de la creación del Fondo de Ahorro y Estabilización, en donde los departamentos que reciben en época de bonanza altos ingresos en materia de regalías, pueden mantener de manera permanente los ingresos por regalías en tiempo de recesión (Escobar \& Martinez, 2014, p.23).

\section{ANTECEDENTES Y MARCO JURÍDICO INTERNACIONAL DE LOS DERECHOS AMBIENTALES}

Como antecedente primario, puede afirmarse que los derechos ambientales encuentran respaldo en la Declaración Universal de los Derechos Humanos de 1948, por el estrecho vínculo con otros derechos, como la vida y la dignidad de la persona, que son directamente afectados con las alteraciones al ambiente.

En 1972, se realizó en la ciudad de Estocolmo, la Convención mundial de las Naciones Unidas sobre el medio ambiente humano, en la que, por primera vez de forma expresa, se hacía referencia a los derechos que se relacionan con el medio ambiente, con la expedición de la Declaración Estocolmo, que generaliza la preocupación global por la contaminación y el manejo ambiental adecuado. Esta convención, introdujo en la política internacional, el tratamiento del tema ambiental, como un límite al modelo económico tradicional, que debe tener en cuenta el manejo de los recursos (Rodríguez \& Páez, 2012, p.55). 
La anterior convención encuentra tres ejes importantes para resaltar, en relación con el medio ambiente. En primer lugar, se hace referencia al derecho que el ser humano tiene en relación con las condiciones adecuadas para disfrutar del medio ambiente, toda vez que garantiza derechos como la libertad e igualdad, que son inherentes a la condición humana. En segundo lugar, establece una obligación común para el género humano, consistente en la preservación del medio ambiente con el fin de permitir a las generaciones futuras el disfrute de un ambiente sano. Por último, hace referencia a la renovación y restauración del ambiente cuando se perjudique por alguna actividad del hombre, teniendo en cuenta que se debe mejorar la tierra para que provea recursos necesarios para sostener las actividades económicas, a partir de la promoción de políticas optimas al interior de los Estados, disposiciones que son acordes a la expedición del decreto 2811 de 1974, por medio del cual se dicta el Código Nacional de Recursos Naturales Renovables y de Protección al Medio Ambiente.

Consecuente con la declaración Universal de los Derechos Humanos y la Convención de Estocolmo, el Pacto Internacional de los Derechos Económicos, Sociales y Culturales, genera su aporte como antecedente de los derechos ambientales, a partir de la consagración del derecho al medio ambiente sano en el artículo 11, que vincula al Estado a la protección, preservación y mejoramiento del medio ambiente (Oficina en Colombia del Alto Comisionado de las Naciones Unidas para los Derechos Humanos, 2001). Este pacto se encuentra ratificado por Colombia, mediante la promulgación de la Ley 74 de 1976, y actualmente hace parte del bloque de constitucionalidad, es decir que se encuentra al mismo nivel de las normas constitucionales.

En 1982 mediante la expedición de la resolución 37/7 del 28 de octubre, la Organización de las Naciones Unidas, promovió la creación de la Carta Mundial de la Naturaleza, promulgando principios que dejan en evidencia la relevancia de la conservación de la naturaleza y la necesidad que encuentra el hombre, para desarrollar un entorno de vida adecuado y en armonía con la naturaleza.

En 1992, la denominada Cumbre de la Tierra, celebrada en la ciudad de Río de Janeiro, permitió que estableciera una nueva concepción sobre los derechos y el medio ambiente, permitiendo sucumbir el medio ambiente a los intereses económicos, tal como lo señala el principio 4, al integrar el medio ambiente a los procesos de desarrollo y no los procesos de desarrollo al medio ambiente, como lo establecía la Declaración de Estocolmo (Rodríguez, 2006, p.43), sin embargo, esta norma se reconoce mundialmente por la dimensión en el desarrollo de los derechos ambientales, que ha inspirado la mayoría de ordenamientos jurídicos que le son afines a los principios contenidos en la declaración, dentro de los cuales se destaca Colombia.

Es importante resaltar que el deterioro ambiental que ha sufrido el planeta con la sobreexplotación de recursos a favor de la industria, debe ser tratado políticamente en todos los niveles, en donde las disposiciones que emanan del marco internacional, se desarrollen ampliamente en los ordenamientos jurídicos internos rescatando aspectos positivos que favorezcan el medio ambiente como patrimonio colectivo, sin embargo, en las economías latinoamericanas en desarrollo, se encuentra en común la carencia de industrias que sean competitivas a nivel mundial, razón por la cual es relevante que se establezcan disposiciones normativas internacionales, que permitan soportar las consecuencias ambientales de la extracción de recursos no renovables así como favorecer los intereses del desarrollo regional.

En la conferencia especializada sobre Derechos Humanos, celebrada en San José de Costa Rica el 22 de noviembre de 1969, se estableció el documento de la Convención Americana de Derechos Humanos, que desarrolla el tema ambiental como un derecho inherente a la condición humana, mediante el denominado Protocolo de San Salvador, que adicionó la disposición de 1969 (Rodríguez, 2006, p.43).

\subsection{EL DERECHO AL MEDIO AMBIENTE SANO EN COLOMBIA}

Los derechos fundamentales, a partir de su consolidación a mediados del siglo XX, se han enriquecido a partir de la propuesta e inclusión en otras clases derechos, que alcanzan la misma connotación, pero que se presentan en otras dimensiones, es decir, que son derechos fundamentales pero que presentan otro tipo de categoría, tal es el caso de la clasificación 
de estos derechos que se denominan Derechos Económicos, Sociales y Culturales y los Derechos Colectivos.

Los Derechos Económicos, Sociales y Culturales se encuentran ligados con la esencia humana, es decir, que son una clase de Derechos Humanos, que contempla una serie de garantías dentro de los cuales se destacan, el derecho al trabajo, a la educación, a una vivienda digna, de igual manera que consagra derechos relacionados con la condición étnica y las expresiones culturales (Anmistía Internacional, 2005). Concretamente, hacen referencia la libertad e igualdad, de los hombres en la dimensión natural la vida.

Los derechos colectivos, son un conjunto de derechos que son inherentes a la condición humana, que tienen la particularidad de reconocerse en virtud de la colectividad, es decir que, el sujeto de derecho, es un determinado grupo social, que tiene determinados intereses susceptibles de ser amparados, para garantizar la subsistencia como grupo o la unidad de grupo, como es el caso del derecho al medio ambiente sano.

El derecho al medio ambiente sano, se reconoce en el ordenamiento jurídico colombiano, como un derecho de carácter fundamental, toda vez que se encuentra ligado íntimamente a la conservación de la especie humana y su entorno, que contiene cierto sentido permisivo para la contaminación a bajo impacto pero que debe ser resarcido (Corte Constitucional, 1992).

La Corte Constitucional colombiana, a través del ejercicio del control concreto de constitucionalidad, que en el caso de derechos colectivos procede de forma excepcional, sostiene que la defensa del medio ambiente sano, es un objetivo del Estado social de derecho, que debe garantizar la supervivencia del ser humano y de las generaciones venideras, razón por la cual debe implementar medidas preventivas y de control en el deterioro ambiental, a partir de la imposición de sanciones legales que permitan la reparación del entorno (Corte Constitucional Colombiana, 2015).

El derecho a un medio ambiente sano es uno de los derechos que ha tomado protagonismo en el escenario jurídico colombiano, este derecho, parte de la necesidad de un manejo adecuado para que la explotación de recursos, permita la sostenibilidad del entorno, así como el manejo de ecosistemas. De igual manera, la relación directa con otros derechos, hacen de este un derecho de carácter fundamental $\mathrm{y}$ colectivo (Corte Constitucional Colombiana, 2015), que encuentra amparo constitucional y que está llamado a la protección por parte de las autoridades y la sociedad en general.

De igual manera que se definen los derechos ambientales, el derecho al medio ambiente sano, contempla una mediación entre la sociedad y la naturaleza, que está orientado a la imposición de límites a fin de garantizar el respeto por los recursos naturales (Rodríguez \& Páez, 2012, p.37). Estos límites, que enmarcan el campo de acción de los intereses económicos producto de la explotación de recursos naturales, presentan un conflicto de intereses que libra tensiones en la mayoría de los casos en la jurisdicción constitucional.

\subsection{MECANISMOS DE DEFENSA AL MEDIO AMBIENTE LA JURISDICCIÓN COLOMBIANA}

Como anteriormente se anotó, el derecho al medio ambiente sano, es un derecho de carácter fundamental, que el constituyente primario lo clasificó como un derecho de carácter colectivo, es decir, que requiere de una manifestación de carácter comunal para exigir la defensa. Por otro lado, se ha señalado por parte de la Corte Constitucional que, de manera excepcional, es procedente la acción de tutela para la defensa de los derechos relacionados al medio ambiente, teniendo en cuenta que se pueda evitar un perjuicio irremediable. Además, es posible la defensa por intermedio de la acción de cumplimiento, como una medida para que se cumplan prescripciones legales, es decir la materialización del principio de legalidad.

En primer lugar, en Colombia es procedente para la defensa del derecho al medio ambiente sano, la acción de tutela, consagrada en el artículo 86 de la Constitución Política, como un mecanismo en virtud del cual cualquier persona puede solicitar el amparo de los derechos fundamentales, ante la Jurisdicción Constitucional. Está orientada a impedir que continúe la afectación al derecho fundamental, mediante la orden de un Juez de la república, y es de cumplimiento inmediato (Cifuentes E., 2010, p.81). 
Se manifiesta en el ordenamiento jurídico, como una acción constitucional de carácter prevalente, es decir, que resulta prioritaria la solución del particular, toda vez que al estar amenazado un derecho fundamental, se puede causar un perjuicio grave en el individuo.

Acorde con la prevalencia, el procedimiento es de carácter sumario, debiéndose fallar en los próximos diez días una vez se allegue la contradicción al escrito inicial. También proceden medidas cautelares en los casos en donde la perturbación al derecho fundamental requiere de intervención inmediata (Cifuentes E., 2010, p.82). Sin embargo, el juez constitucional, deberá evaluar la situación y verificar que en ordenamiento jurídico no exista otro procedimiento para buscar el amparo del derecho, teniendo la acción de tutela una manifestación de carácter subsidiario (Pinzón, 2009, p.2).

En relación con el derecho al medio ambiente sano, la acción de tutela no aplica en todo momento, en virtud de que existen procedimientos alternos que impiden la aplicación de esta acción constitucional, pero en virtud de los pronunciamientos jurisprudenciales del Tribunal Constitucional, esta acción procede cuando se busque evitar un perjuicio irremediable. En este caso, se tutelan los derechos de las demás personas de la colectividad que no ejercieron el derecho, lo cual se verá reflejado en el fallo de tutela (Cifuentes E, 2010, p.83).

Por otro lado, la acción de cumplimiento es otro mecanismo de carácter constitucional que permite acceder al amparo de los derechos ambientales. Se encuentra consagrada en el artículo 87 de la Carta Política, y permite solicitar al juez, el cumplimiento de disposiciones con fuerza material de ley, o de actos administrativos, que están siendo evadidas por parte de alguna autoridad o un particular. Esta acción desarrollada en virtud de la Ley 393 de 1997, procura el cumplimiento del principio de legalidad que es la base fundamental del Estado social de derecho.

Cualquier persona puede impetrar demanda ante las autoridades judiciales, con el fin de que se cumpla una prescripción con fuerza material de ley o acto administrativo. La competencia para conocer de la acción, cuando se trate de normas con fuerza material de ley o de actos administrativos, corresponde a los jueces administrativos, del domicilio del accionante.

Excepcionalmente procede en contra de particulares, los cuales deberán cumplir funciones públicas, o estar relacionadas con la norma que se presume incumplida, la demanda podrá dirigirse en contra del particular o la autoridad que incumple, en los casos en que sea los dos causantes del incumplimiento. Requiere de una reclamación previa a la autoridad, en donde se indica el posible incumplimiento de una disposición normativa, de igual manera que requiere la contestación negativa o el silencio durante los siguientes diez días a la presentación del escrito. (Cifuentes E., 2010, p.83).

El procedimiento goza de un trámite preferencial, que solo desplaza la acción de tutela. Deberá ser admitida por parte del Juez, dentro de los siguientes tres días a la presentación de la demanda, y deberá resolverse de fondo dentro de los veinte días siguientes.

Por último, las acciones populares constituyen otro mecanismo por el cual los particulares pueden acceder a la protección de los derechos al medio ambiente sano. Esta acción encuentra antecedentes en el Código Civil, como una acción que pretendía principalmente la protección de los bienes de uso público. Posteriormente, en virtud del Decreto 3466 de 1982 y la Ley 9 de 1989, se le designó a la acción popular como el mecanismo idóneo para la defensa de derechos relacionados con el espacio público y los derechos al medio ambiente (Bastidas \& Elias, 2010, p.21). Esta acción podía ser ejercida en contra de particulares o autoridades que perturbaran los derechos señalados.

La Constitución Política de 1991 determinó que el desarrollo de las acciones populares fuese por medio del ministerio de la Ley, para permitir el amparo de una serie de derechos de carácter colectivo, dentro de los cuales se destaca el medio ambiente entre otros. La disposición que desarrolla este derecho se llevó a cabo con la promulgación de la Ley 472 de 1998 por medio de la cual se desarrolla el artículo 88 de la Constitución Política de Colombia en relación con el ejercicio de las acciones populares y de grupo y se dictan otras disposiciones. 
La naturaleza de las acciones populares, está orientada a la protección de bienes comunes a las personas, razón por la cual cualquier persona puede solicitar judicialmente su protección, por considerar la lesión de un derecho común al de la comunidad. Los posibles daños que emanen de la vulneración de estos derechos deben orientarse a la indemnización de los perjuicios causados. Sin embargo, es importante resaltar que, si bien la acción tiene un fin indemnizatorio, los antecedentes que tienen origen en el derecho privado, hacen referencia a que es una acción de carácter preventivo, toda vez que no es necesario esperar a que exista un prejuicio para validar la procedencia de la acción (Corte Constitucional, 1994).

De igual manera que las acciones relacionadas anteriormente, la acción popular, encuentra un trámite preferencial, que no desplaza los tramites de la Acción de Tutela y la Acción de cumplimiento. El procedimiento establece de manera opcional la reclamación ante la autoridad administrativa, es decir, que no es necesario interponer recurso alguno para acudir ante las autoridades para que amparen el derecho colectivo amenazado.

La competencia para conocer de las acciones populares corresponde inicialmente a la jurisdicción de lo Contencioso Administrativo, quien conocerá de los procesos que se den con ocasión a la expedición de actos administrativos, acciones y omisiones de las entidades públicas, o de los particulares que ejerzan funciones públicas. En los demás casos, la competencia para conocer le corresponde a la jurisdicción ordinaria civil. En los dos casos conocerán los jueces del circuito.

\subsection{CONFLICTO AMBIENTAL DE LOS RECURSOS HÍDRICOS Y EL MATERIAL PARTICULADO DE CARBÓN EN EL AIRE, EN LA ZONA DE EXPLOTACIÓN MINERA DE EL CERREJÓN}

La contaminación de las fuentes hídricas en la cuenca del Río Ranchería, es el principal conflicto ambiental que aqueja a la población del sur de la Guajira, que confronta los intereses económicos de las empresas que destinan sus recursos a la explotación minera, frente a la necesidad de surtir agua a los municipios del departamento.

Las técnicas de explotación minera a cielo abierto generan una cantidad considerable de partículas aéreas que son perjudiciales para la salud humana y los ecosistemas de las periferias de la explotación, encontrando una necesidad en la utilización de agua para aplacar las partículas que se encuentran en el aire. De conformidad con lo señalado anteriormente, las técnicas de explotación en El Cerrejón requieren de la utilización de aguas superficiales, así como de aguas subterráneas, que varían en la pureza según la aplicación (Báez \& Trujillo, 2014, p.44).

Los pobladores del sur de la Guajira, que son testigos directos de impacto sobre el medio ambiente, que produce la explotación minera, acuden espontáneamente al ejercicio de instrumentos legales, para la defensa de los derechos al medio ambiente, (Centro de Investigación y Educación Popular, 2016),sin embargo, las organizaciones de pobladores que se atreven a denunciar las alteraciones en los recursos hídricos, permiten evidenciar el grado de perturbación al ambiente que la operación minera genera, que se encarga de mostrar una evidencia sobre las fuentes hídricas con respecto a la acumulación de sedimentos, residuos de carbón sobre el lecho de los ríos, presencia de botaderos inactivos, entre otros (Centro de Investigación y Educación Popular, 2016).

Por otro lado, el material particulado que se evidencia en el aire y las partículas de carbón que se desplazan con este a causa de la actividad extractiva, de conformidad con un informe de la Agencia Nacional de Licencias Ambientales (ANLA) presentado en 2014 dentro de la sentencia T- 256 de 2015, durante los monitoreos realizados por esta autoridad durante los años 2010-2014, las emisiones de Partículas Suspendidas Totales (PST), se encuentran por debajo de los criterios establecidos para la actividad, que corresponden a $85.5 \mu \mathrm{g} / \mathrm{m} 3$ para 2014 (Corte Constitucional, Sentencia T-256, 2015).

Atendiendo a lo dispuesto en la Resolución 610 de 2010, emitida por el Ministerio de Ambiente, Vivienda y Desarrollo Territorial, las emisiones de PST diarias permitidas, de conformidad con el artículo 4, corresponden a 300 PST. En contraste con el informe presentado por la ANLA en 2014, se evidencia que las emisiones diarias monitoreadas en las periferias de la zona de explotación de El Cerrejón oscilan entre los 60 PST y 210 PST, acordes con la disposición normativa, siendo los más altos registrados entre enero y mayo de 2013. 
De conformidad con la medición anual de SPT, se puede evidenciar que en el periodo 2010 2014, se presentan variables, en donde la mayor concentración de emisiones corresponde a los años 2012, 2013 y 2014, con un promedio de 85 PST, que de conformidad con lo permitido se encuentra al límite por año (Corte Constitucional, Sentencia 256, 2015).

Por otro lado, la Corporación Autónoma Regional de la Guajira, que ha desplegado esfuerzos por realizar estudios con respecto a las emisiones de material particulado en las poblaciones periféricas a la zona de explotación de El Cerrejón, presentan entre los años 2011 a 2013, un registro de emisiones anuales de 68, 63 y 84 PTS correspondientemente, evidenciando un crecimiento en las emisiones que se ha incrementado para el último año.

Ahora bien, la relación de las emisiones de las partículas de carbón que generan un conflicto con el derecho al medio ambiente sano se evidencia en el impacto que estas tienen sobre la salud de las personas, razón por la cual es importante observar el tratamiento de enfermedades que se prestan en los centros médicos de las poblaciones cercanas a las zonas de explotación.

En 2015, el Instituto Nacional de Salud por intermedio del Sistema en Salud Pública - SIVIGILA, presentó un informe que contiene el estudio del ingreso por urgencias del año 2014 de la población de los corregimientos de Patilla y Chancleta ubicados en cercanías a la zona de explotación minera, en el sur del departamento de la Guajira, en donde se registra un total de 14.241 ingresos, de los cuales 2526 presentan síntomas de la patología denominada Infección Respiratoria Aguda (IRA) (Corte Constitucional, Sentencia 256, 2015).

El departamento de la Guajira, por intermedio de su secretario de salud, reportó que para el 2014 en el municipio de Barracas, que se encuentra en las periferias de la mina de El Cerrejón, existe una prevalencia de IRA desarrollada en la población de menores de cinco años, que se ha incrementado a partir del 2011. El informe presentado muestra una diferencia de 150 casos reportados para 2011, el incremento de 1598 en 2013 y 1208 en 2014(Corte Constitucional, Sentencia 256, 2015).

Con respecto a la población de personas con más de cinco años, reporta el informe del Secretario Departamental que, durante el 2011, se reconocieron 202 casos de IRA, registrando un incremento en los años siguientes con 1286 casos de IRA para el 2012, 2124 para el año 2013 y 1348 para el 2014.

En síntesis, se evidencia un registro de incremento de casos de infecciones respiratorias, que se asocian a la actividad minera de carbón, resultando preocupante tanto para las comunidades que habitan la zona, como para las autoridades, atendiendo a los índices de crecimiento de enfermedades respiratorias, que si bien no se ha relacionado directamente con la extracción de carbón, reporta un crecimiento que va de la mano con el aumento de extracción y el crecimiento de la emisiones de partículas en el aire.

Con respecto a las fuentes hídricas es importante destacar que la operación minera encuentra un uso importante de este recurso, con la finalidad de reducir las partículas en el aire, sin embargo, la contaminación evidente de las fuentes hídricas a causa del crecimiento de las zonas de explotación, y la necesidad del líquido para la subsistencia, permiten hacer un juicio de valor que desfavorece la explotación minera, toda vez que el agua como recurso es fundamental para cualquier especie animal, a diferencia de la actividad económica que se puede limitar con unas repercusiones leves en la economía.

Las condiciones de salubridad de las etnias wayuu, kinqui, ika, kogui y wiwa que habitan el territorio de la Guajira, carecen de recursos para dignificar su existencia, haciendo evidente la crisis la ausencia de acueductos o pozos que suministren agua potable, y la carencia del preciado líquido que es escaso en todo el departamento esto se contrasta con una operación minera que consume veintidós mil litros de agua diarios de todas las calidades para soportar la operación, lo que hace preocupante la situación y refleja una tensión que debe resolverse bajo la coacción del Estado que debe favorecer los intereses de estas etnias.

\section{EJERCICIO DE LOS DERECHOS AMBIENTALES EN REFERENCIA CON LA EXPLOTACIÓN CARBONÍFERA DE EL CERREJÓN}

El ejercicio de los derechos ambientales, en relación con la zona de explotación del Cerrejón, tiene su desarrollo en instancias judiciales, que 
son promovidas y resueltas por intermedio de la jurisdicción constitucional, atendiendo a la naturaleza de los derechos que en Colombia son de carácter fundamental.

Como anteriormente se indicó, los mecanismos por los que la ciudadanía puede acceder para la defensa de los derechos ambientales son variados, sin embargo, una vez revisadas las sentencias que reposan en la Corte Constitucional y en el Consejo de Estado en relación con la explotación minera del Cerrejón, se evidencia que es precario el uso de vías judiciales para la defensa del derecho al medio ambiente sano, razón por la cual se procederá al examen, de cada sentencia, con la intención de extraer las repercusiones económicas que tiene el ejercicio de estos derechos con respecto a la explotación minera y determinar las repercusiones en los ingresos por regalías.

En el desarrollo de las competencias designadas al Consejo de Estado en relación con el ejercicio de las Acciones populares y el derecho al medio ambiente sano, que se presentan con ocasión a la explotación minera del Cerrejón, no se evidencia jurisprudencia al respecto, lo que permite asegurar que existe un precario uso de acciones constitucionales para la defensa de estos derechos. De igual manera, se evidencia la necesidad de informar a la población que en gran porcentaje pertenece a las comunidades étnicas, de los derechos de los cuales son titulares.

Por su parte, la Corte Constitucional, se ha pronunciado también en forma limitada con respecto a los derechos ambientales de los que deben gozar las poblaciones que habitan la periferia de la zona de explotación de El Cerrejón.

Sin embargo, en mayo de 2015, se pronunció en virtud del fallo de tutela T - 256 de ese mismo año, en donde se presentan antecedentes en la demanda, que permiten vislumbrar la compleja situación de las comunidades étnicas de la región, así como el impacto ambiental de la operación minera, que se ha realizado por más de treinta años.

\subsection{ANÁLISIS DE LA SENTENCIA SU- 442 DE 1997, COMO ANTECEDENTE DE LA REGULACIÓN DE LOS DERECHOS AL MEDIO AMBIENTE}

La sentencia SU- 442 de 1997, es producto de las acciones de tutela promovidas por Francisco Antonio Escobar Silebi y Otros en contra de la Corporación Autónoma del Magdalena, El Distrito Turístico, Cultural e Histórico de Santa Marta y Metroagua S.A., bajo el radicado No. T-120.950, así como el expediente No. T-120.950 promovido por el representante legal del Edificio Mendiguaca de la ciudad de Santa Marta, en contra de la empresa Metroagua S.A., por la presunta contaminación de los recursos hídricos que se ven afectados por la negligencia de las autoridades distritales para el manejo de las aguas residuales.

Ambas solicitudes de amparo fueron denegadas por los falladores de instancia, teniendo en cuenta la existencia de otros mecanismos idóneos para la defensa de este tipo de derechos, omitiendo el análisis de fondo que es desarrollado a partir de la intervención de la Corte Constitucional.

En abril de 1997, mediante Auto proferido por la sala sexta de revisión de tutelas de la Corte Constitucional, se decretaron una serie de pruebas con el fin de evidenciar el deterioro del medio ambiente en las inmediaciones de las zonas turísticas de Santa Marta, en donde se ordenó al Servicio Departamental de Salud del Magdalena, la realización de pruebas de laboratorio para verificar la calidad del agua potable que se suministra por parte de la empresa de servicios públicos METROAGUA, solicitud que se replicó al Ministerio del Medio Ambiente y a la Corporación Autónoma de Magdalena, con la finalidad de que se informara la cantidad de partículas de carbón que se encuentran en el Aire, a causa de la operación del puerto de CarboAndes, además de contemplar las zonas que afectan de los puertos de Prodeco y de la Drummond.

La práctica de pruebas solicitadas por los magistrados del despacho, obedecen principalmente a la necesidad de evidenciar el impacto de las partículas del carbón sobre la salud humana, teniendo en cuenta que es un problema evidente en la región en donde se impulsaron las acciones motivo de análisis, toda vez que para la sala, la invocación para la protección del derecho al medio ambiente sano como una obligación del Estado, permite realizar recomendaciones que recaigan sobre la actividad transportadora de carbón, que se centra en los puertos de embarque en las cercanías de los sectores residenciales de Santa Marta. 
Con respecto al estudio presentado por el Ministerio de Salud, en relación con el impacto de la operación minera de carbón y los a los derechos al medio ambiente, es importante resaltar que los efectos de la exposición al carbón, presenta repercusiones a la salud, con la evidencia de patologías como la rinitis o la Neumoconiosis del carbón, cuyos daños son irreversibles en la salud, de igual forma que ayuda al deterioro de la salud y contribuye a la complicación de otras enfermedades.

Por otro lado, un estudio epidemiológico, social y ambiental realizado a la población laboral de El Cerrejón zona Centro, realizado por el Instituto del Seguro Social y el Ministerio de Salud, entre otros, permite evidenciar que, en los cuatrocientos diez trabajadores, cincuenta y uno padecen de Neumoconiosis, así como 189 presentan síntomas de Enfermedad Neumoconiótica.

Las conclusiones del anterior informe enuncian que la actividad minera genera un impacto sobre los gastos en salud del Instituto del Seguro Social, representando la cuarta actividad económica. De igual manera se da a conocer, que la exposición al material particulado del carbón no solo tiene repercusión en la salud de las personas que se exponen como resultado de actividades profesionales, toda vez que, comprometen la salud de las comunidades que en las periferias de las zonas de explotación soportan la exposición a las partículas aéreas.

Es importante resaltar que de conformidad con el acervo probatorio que reposa en el expediente, se encontró una exposición a las partículas de carbón en las zonas portuarias de la Drummond, Prodeco y Carboandes, empresas que se dedican a la manipulación del carbón, y que operan en las periferias del Distrito Turístico de Santa Marta, por lo cual resulta importante una intervención de carácter urgente, con el fin de prevenir el deterioro de la salud de las comunidades que se encuentran en riesgo.

Como consecuencia del análisis de las pruebas, que se relacionan con la extracción de carbón allegadas al expediente, la Corte Constitucional expone en la parte resolutoria de la sentencia que es motivo del presente análisis, recomendar al Ministerio del Medio Ambiente, elaborar y ejecutar un proyecto de control integral al manejo del carbón, que incluya la operación de transporte, que genera perjuicios en la salud de las personas como se evidencia.

\subsection{ANÁLISIS DE LA SENTENCIA T- 046 DE 1999, COMO ANTECEDENTE DE LA REGULACION DE LOS DERECHOS AL MEDIO AMBIENTE}

La Sentencia T-046 de 1999, es producto de la acción de tutela promovida por Ricardo Correal Morillo, en la calidad de Director de la Dirección Nacional de Recursos y Acciones Judiciales de la Defensoría del Pueblo, producto del poder conferido por un grupo de personas que encuentra vulnerado el derecho al medio ambiente por la actividad económica de la empresa C.I. PRODECO PRODUCTOS DE COLOMBIA S.A. -C.I. PRODECO S.A, consistente en la recepción, maneo y embarque de carbón procedente de diversas zonas del país.

Los hechos que sustentan la acción de tutela, parten de la evidente contaminación de la zona turística de Santa Marta, teniendo en cuenta que los puertos de embarque que se ubican a 19 kilómetros de la zona turística, generan contaminación por emisión de partículas que provienen del Carbón.

Se reconoce por parte de los accionantes, que la compañía ha hecho una inversión en tecnología, con la intención de mitigar el impacto ambiental de la actividad de transporte y embarque, sin obtener resultados positivos que beneficien el medio ambiente, razón por la cual es necesaria la intervención de las autoridades para garantizar el desarrollo adecuado de la actividad económica sin que genere daños colaterales en la población.

La empresa accionada, por intermedio de apoderado judicial, presentó una excepción a las pretensiones, alegando la subsidiariedad de la acción de tutela, además indicó que se ha implementado el uso de las tecnologías necesarias para controlar las emisiones aéreas, además de establecer procedimientos acordes a la normatividad vigente, que permiten reducir el impacto del deterioro ambiental y como consecuencia disminuir los perjuicios para la población.

El 21 de julio de 1998, la Sala Penal del Tribunal Superior de Santa Marta, concedió el amparo constitucional, teniendo como fundamento, que la acción solicitada alegaba una 
vulneración al medio ambiente, que se relaciona con los derechos a la vida y a la salud, lo que hacen procedente el examen del Tribunal.

Posterior al análisis de las pruebas aportadas al proceso, se evidenció que los procedimientos implementados en la manipulación del mineral por parte de la empresa accionada, encontraban inconsistencias que permiten una vulneración a los derechos a la vida, además agregó que, según lo descrito en documento por parte del Departamento Nacional de Planeación, la única zona en donde no podría causar repercusiones para la salud las actividades relacionadas con el carbón, fue en Bahía Portete, ubicada en el norte del departamento de la Guajira, que se encuentra en zona desértica.

El 12 de septiembre de 1998, la sala Penal de la Corte Suprema de Justicia, confirmó el fallo de primera instancia, proferido por la sala Penal del Tribunal Superior de Santa Marta, aduciendo que la perturbación a la que están sometidos los habitantes del distrito de Santa Marta, es evidente de conformidad con el material probatorio aportado, además de aclarar que, no es necesario esperar a que se evidencie un impacto mayor que genere daños irreparables tanto para el medio ambiente como para los habitantes.

Por otro lado, es importante resaltar que la relación entre la promoción de acciones constitucionales que ofrecen un amparo a los derechos al medio ambiente, no deben desviarse a factores diferentes a los derechos fundamentales, teniendo en cuenta que el turismo y el tránsito de carreteras encuentran diferencias para la protección por vía de tutela.

En conclusión, la Corte Constitucional confirma las decisiones de instancia, toda vez que, a partir de lo examinado, se estima que la responsabilidad para la protección de los derechos ambientales parte de una obligación de carácter constitucional para el Estado, que debe estar respaldada por las acciones de los particulares, razón por la cual la empresa accionada deberá proceder a la reducción del impacto de las emisiones en el aire. Por otro lado, se deberá ejercer control para dicha actividad por la Corporación Autónoma del Magdalena, con la intención de que se permita alcanzar los fines de protección para los derechos fundamentales al medio ambiente en conexidad con la salud y la vida.

\subsection{LA INTERVENCIÓN RELEVANTE DE LA SENTENCIA T - 256 DE 2015, EN RELACIÓN CON LA EXPLOTACIÓN MINERA DE EL CERREJÓN}

Como consecuencia de irregularidades relacionadas con la reubicación de pobladores, y el impacto ambiental que repercute en la salud de las personas, la recientemente reconocida Comunidad de Negros afrodescendientes, perteneciente a los corregimientos de Patilla y Chancleta del municipio de Barrancas, en el departamento de La Guajira, por intermedio de apoderado judicial, promovió acción de tutela en contra de contra la empresa "Carbones del Cerrejón Limited", referenciando situaciones que recogen el drama de la población Guajira de ese municipio (Corte Constitucional. Sentencia T-256, 2015).

Los hechos relacionados en la demanda tienen como primer antecedente la explotación ejercida por la empresa accionada en los territorios que ocupan por un periodo superior a los treinta años. Minería que ha sido ejercida a cielo abierto y que, hoy en día, se reconoce como una de las zonas de explotación de Carbón más grandes del mundo.

Producto del asentamiento en el sur de la Guajira para la explotación minera de Carbón, que ha sido ejercida por décadas, en agosto de 2010, contando con el aval del Ministerio de Ambiente y Desarrollo Sostenible, se autorizó a la empresa "Carbones del Cerrejón Limited", proceder con la reubicación de las comunidades ancestrales de los corregimientos de Patilla y Chancleta, que pertenecen al municipio de Barrancas, ubicados al sur de la Guajira. La reubicación debería realizarse en un periodo que no superara el mes de diciembre del año siguiente.

Como consecuencia del término indicado por el Ministerio de Ambiente y Desarrollo Sostenible, la empresa accionada, inició la construcción de viviendas en zona urbana, con la intención de ofrecer a los pobladores la reubicación que les permitiera acceder a mejorar la calidad de vida. La respuesta de la población, fue aceptada por sectores, que por un lado, permitieron la ubicación en el nuevo complejo de viviendas. Como sector disidente, la Comunidad de Negros afrodescendientes, aunados a pobladores campesinos que habitan la zona, los cuales suman un aproximado de cuarenta familias, presentaron renuencia a la reubicación, con la intención de defender el territorio que han ocupado por años, que 
les permite la conservación de la identidad social, así como rasgos culturales propios de su comunidad.

Las características poblacionales de las familias que han resistido a la reubicación cuentan, en primer lugar, con personas que no tienen ninguna connotación étnica, pero que han ocupado el terreno por un periodo superior a diez años. En segundo lugar, se compone de familias de la etnia Wayuú, que de igual forma se asentaron en los corregimientos por un periodo superior a los diez años y, por último, la comunidad de afrodescendientes ancestrales que cuenta con un reconocimiento en virtud de la resolución 018 del 2013 del Ministerio del Interior. Todos los pobladores señalados, son renuentes a la reubicación en zonas urbanísticas, que impiden las manifestaciones culturales que recaen en su identidad étnica y condición socio-económica.

En las sentencias de instancia, proferidas en primer lugar por el Juez Promiscuo Municipal de Barrancas y el Juez Promiscuo de Familia de San Juan del Cesar, se rechazaron los argumentos de la demanda, por no reunir requisitos de subsidiariedad, que permitieran el amparo constitucional por vía de tutela.

Como consecuencia de la revisión efectuada por la Corte Constitucional, posterior a la práctica de pruebas que permiten evidenciar a fondo las situaciones fácticas analizadas por la jurisdicción en sede de tutela, la Corte se pronunció en relación con los derechos al medio ambiente, bajo un análisis que se soportó con los estudios de la Universidad Nacional de Colombia, la Universidades Javeriana, la Universidad del Rosario y la Universidad de los Andes.

En primer lugar se resalta, por intermedio de la sentencia referenciada, que la Constitución Política de 1991 consagró un deber en cabeza del Estado para la protección al derecho al medio ambiente sano, el cual se complementa con el análisis jurisprudencial contenido en la sentencia T-411 de 1992, que a su vez contempla el concepto de "Constitución ecológica", en virtud del cual se evidencia que a lo largo de la Constitución existen disposiciones que resaltan la importancia del medio ambiente y la necesidad de la protección (Corte Constitucional. Sentencia T-256, 2015).
En segundo lugar, se hace referencia a la necesidad de la protección del Agua como un derecho fundamental, que garantiza la vida del ser humano en condiciones mínimas, contrastando este derecho, con las condiciones precarias que evidencian una crisis humanitaria en el departamento de la Guajira. Esta crisis se soporta en el informe presentado por la Defensoría del Pueblo llamado "Crisis Humanitaria en La Guajira 2014", que pone en evidencia las condiciones de desnutrición que sufre la población Wayuú, a causa de la falta de agua potable, así como la carencia de servicios básicos y la composición de una red hospitalaria que carece de recursos para asistir a la población del departamento.

Es importante destacar que las condiciones precarias que se encuentran contenidas en el informe, no se atribuyen a la explotación minera, toda vez que son una suma de factores los que se han configurado para determinar la crisis de la población de la Guajira.

La Decanatura Académica de la Facultad de Medicina de la Universidad Javeriana, mediante informe remitido al despacho de la magistrada sustanciadora, indica que las patologías producto de la inhalación de carbón pueden ser diferentes, y son conocidas como la bronquitis, el enfisema centrolobulillar, la silicosis y la neumoconiosis, esta última se relaciona directamente con la explotación mineral de carbón, y puede retardar en los síntomas por un periodo de aproximadamente diez años.

La Dirección de Promoción y Prevención del Ministerio de Salud, mediante solicitud de la magistrada sustanciadora, aportó un informe en febrero de 2015, argumentó que existe una ausencia de estudios realizados por esta autoridad en el sur de la Guajira, que le impide dar respuesta al requerimiento, para determinar si existe una relación entre el deterioro a la salud de los lugareños con la explotación minera del Cerrejón. Sin embargo, a modo general, concluyó que las exposiciones a material articulado repercuten en la salud de los animales y las personas, e incrementa las tasas de mortalidad, de conformidad con estudios que recaen sobre la materia.

Como consecuencia del análisis anterior, en contraste con los hechos presentados en la acción de tutela, en relación con los derechos ambientales 
se ordena la protección constitucional, a partir de la revocatoria de las sentencias proferidas por el Juez Promiscuo Municipal de Barrancas y el Juez Promiscuo de Familia de San Juan del Cesar.

\section{CONCLUSIÓN}

Como conclusión es posible indicar que las acciones constitucionales respecto al ejercicio del derecho a un ambiente sano, en relación con la explotación minera de El Cerrejón en el periodo 2010-2015, han generado unas repercusiones de carácter legal y ha impuesto límites al ejercicio de la actividad minera en la Guajira. Esto por cuanto la Corte Constitucional, por medio de la sentencia T- 256 de 2015, impuso obligaciones legales y limitó la expansión de la actividad minera en los corregimientos de Chancleta y Patilla. Por otro lado, si bien es cierto que se ha presentado un incremento en la recepción de regalías producto del aumento de la producción, la limitación al ejercicio de la actividad minera a raíz de la presentación de acciones constitucionales, podría tener repercusiones en la recepción de regalías.

De otro lado es importante observar cómo la tutela puede proceder de manera extraordinaria en el ejercicio de derechos que no hacen parte de los denominados "fundamentales", pero cuya conexidad y posibilidad de protección inmediata encuentran en esta acción un recurso fundamental para la protección de la vida del ser humano en relación con el medio ambiente del cual depende su vida.

Queda también por revisar atentamente la suerte que correrán estos derechos en estos tiempos de cambio climático y calentamiento global, por cuanto su protección se reclama tan urgente como el análisis pendiente de si las acciones reservada especialmente para ellos han resultado, o serán suficientes para la garantía de un futuro ambientalmente sostenible con el modelo de desarrollo del país.

\section{BIBLIOGRAFÍA}

- Anmistía Internacional. (2005). Derechos humanos para la dignidad humana: una introducción a los derechos económicos, sociales y culturales. Madrid: Editorial Amnistía Internacional.

- Aramburo, J. (1984). Curso de derecho minero. Bogotá: Temis.

- Báez, L., \& Trujillo, F. (2014). Biodiversidad en Cerrejón. Carbones de Cerrejón. Bogotá: Fundación Omacha, Fondo para la Acción Ambiental la Niñez.

- Bastidas, L., \& Elias, A. (2010). La acción popular: herramienta del ministerio público en la defensa del medio ambiente. Bogotá: Pontificia Universidad Javeriana.

- Benítez, N. (2013). Caracterización del nuevo sistema de regalías y su efecto fiscal en los municipios de sexta categoría del departamento de Boyacá, Colombia. Finanzas y Política Económica, Vol.5, No. 1, enero-junio, pp.151-178.

- Bonet, J., \& Urrego, J. (2014). Documentos de trabajo sobre economía regional. Bogotá:
Banco de la República.

- Cadenas, A. (2004). Vuelta al carbón y la biomasa con actuales innovaciones tecnológicas. Buenos Aires: ANI - Academia Nacional de Ingeniería.

- Cafferatta, N. (2004). Introducción al derecho ambiental. México: Instituto Nacional de Ecología.

- Cámara de Comercio de la Guajira. (2015). Informe Socioeconómico de la Guajira 2015. Riohacha: Departamento y Promoción Desarrollo Empresarial.

- Cárdenas, A. (2004). Vuelta al carbón y la biomasa con actuales innovaciones tecnológicas. Buenos Aires: ANI - Academia Nacional de Ingeniería.

- Cárdenas, M., \& Reina, M. (2008). La minería en Colombia: impacto socioeconómico y fiscal. Bogotá: Fundación para la Educación Superior y el Desarrollo.

- Castro, A. (2000). De la asociación minera a la concesión moderna en explotación 
de carbón. Bogotá: Pontificia Universidad Javeriana - Facultad de Ciencias Jurídicas.

- Centro de Investigación y Educación Popular. (2016). Minería, conflictos agrarios y ambientales en el sur de La Guajira. Bogotá: Centro de Investigación y Educación Popular / Programa por la Paz (CINEP/PPP).

- Cerrejón. (2017). Cerrejón Minería Responsable. Recuperado el 20 de 02 de 2017, de http://www.cerrejon.com/site/ nuestra-empresa/historia.aspx

- Cifuentes, E. (2010). La acción de tutela en Colombia. Santiago de Chile: Red Idus et Praxis.

- Cifuentes, P. (2008). Impuestos tributarios en la gran minería del Carbón. Bogotá: Escuela Superior de Administración Pública.

- Córdoba, M. (2009). Finanzas públicas: soporte para el desarrollo del Estado (2a. ed.). Bogotá: Ecoe Ediciones.

- Corte Constitucional. (1992). Sentencia $\mathrm{T}$ - 536. Colombia: Corte Constitucional Colombiana.

- Corte Constitucional. (2003). Sentencia C - 628. Colombia: Corte Constitucional Colombiana.

- Corte Constitucional Colombiana. (2015). Sentencia C - 449. Colombia: Corte Constitucional Colombiana.

- Corte Constitucional Colombiana. (2015). Sentencia T - 256. Colombia: Corte Constitucional Colombiana.

- Corte Constitucional Colombiana. (2016). Sentencia C -389. Colombia: Corte Constitucional Colombiana.

- Corte Constitucional. (1994). T.482. Colombia: Corte Constitucional Colombiana.

- Departamento Nacional de Planeación. (1999). Lineamientos de política para la implementación de operaciones relacionadas con la venta de la participación accionaria de la Nación en CARBOCOL. Bogotá: Documento conpes 3046.

- Departamento Nacional de Planeación.
(2011). Equidad, ahorro, competitividad y buen gobierno. Bogotá: Imprenta Nacional de Colombia.

- Díaz, M. (2004). Análisis, control y evaluación de riesgo de fenómenos gaseodinámicos en minas de carbón. Oviedo: Ediuno - Universidad de Oviedo.

- Dirección de Regalías. (2007). Actualización de la cartilla: "Las Regalías en Col Bogotá: Departamento Nacional de Planeación.

- Domínguez, A. (2001). La Revolución Industrial: algunos logros de la ingeniería. Buenos Aires: Academia Nacional de Ingeniería.

- Duque, A. (2012). El Derecho fundamental a la Consulta Previa, Libre e Informada en el Caso de la Población Afrocolombiana.

- Duque, A. (2012). El Derecho fundamental a la Consulta Previa, Libre e Informada en el Caso de la Población Afrocolombiana. Bogotá.

- Escobar, A., \& Martínez, H. (2014). Sector Minero colombiano actual. Unidad de Planeación Minero Energética.

- Fuentes. (2013). El presupuesto en el marco de la planeación financiera: conceptos, doctrina y jurisprudencia. Bogotá: Editorial Universidad del Rosario.

- Fuentes, A., \& Delgado, M. (2016). Contribución fiscal de la operación minera de El Cerrejón a las finanzas públicas y situación fiscal de las entidades territoriales de su área de influencia en el departamento de la guajira 2000-2014. Bogotá: Centro de Investigación económico y social - Fedesarrollo.

- González, N. (2014). La concesión minera en Colombia: un análisis desde el marco normativo y regulatorio frente a los principios de seguridad y estabilidad jurídica. Bogotá: Universidad Colegio Mayor de Nuestra Señora del Rosario.

- Hernández, L. (2010). Regalías: ¿A dónde irán? Bogotá: Escuela Superior de Administración Pública. 
- López, P., \& Ferro, A. (2006). Derecho Ambiental. México: IURE Editores SA.

- Ministerio de Minas y Energía. (2014). Política nacional para la formalización de la minería en Colombia. Bogotá: Ministerio de Minas y Energía.

- Oficina en Colombia del Alto Comisionado de las Naciones Unidas para los Derechos Humanos. (2001). Derechos económicos, sociales y culturales. Bogotá: Naciones Unidas.

- Ohara, J. (1981). El proyecto de El Cerrejón. Huellas 2 Uninorte, 34-36.

- Ortega, A. (2016). Economía colombiana (5a. ed.). Bogotá: Ecoe Ediciones.

- Palacio, C. (2015). Evolución tributaria en Colombia desde el año 1990 hasta 2014, Gobierno Nacional Central. Bogotá: Facultad de estudios a distancia, Universidad Nueva Granada.

- PBI Colombia. (2011). Minería en Colombia: ¿a qué precio? Bogotá: PBI Colombia.

- Piedrahíta, J., \& Salazar, V. (2012). Impuesto al Valor Agregado en Colombia. Motivaciones, beneficiarios y servicio al país. Medellín: Universidad de Medellín, Facultad de ciencias económicas.

- Pinzón, M. M. (2009). La acción pública de inconstitucionalidad en la Colombia del siglo XIX a través de una ley sobre el colegio Mayor del Rosario. Bogotá: Red Revista Estudios Socio-Jurídicos.

- Puentes, G. (2013). El presupuesto en el marco de la planeación financiera: conceptos, doctrina y jurisprudencia. Bogotá: Editorial Universidad del Rosario.

- Ramos, G. (2002). La minería Colonial y Republicana. Credencial historia edición 151.

- Rettberg, A., Ortiz, J., \& Yañez, S. (2014). Legislando minas Breve recuento de la legislación minera en Colombia (1829
- 2001). Bogotá: Documentos CEDE 38 Universidad de los Andes.

- Rodríguez, A., (2006). Los derechos humanos y medio ambiente. Bogotá: Editorial Universidad Javeriana.

- Rodríguez, G., \& Páez, I. (2012). Temas de derecho ambiental: una mirada desde lo público. Bogotá: Editorial Universidad del Rosario.

- Rudas, G. (2014). La minería de carbón a gran escala en Colombia: impactos económicos, sociales, laborales, ambientales y territoriales. Análisis 1, 5-20.

- Sánchez, H. (2014). El impuesto al patrimonio como mecanismo de financiación del Estado colombiano y su incidencia en la inversión y acumulación de capital durante los años 2002 a 2014. Un análisis de sus aspectos jurídicos, económicos y sociales. Bogotá: Universidad Católica de Colombia.

- Sarmiento, N. (2008). ¿Bondad o estrategia? tejiendo responsabilidad social en el mundo del carbón. Bogotá: Ceso Ediciones Unidades - Universidad de los Andes.

- Tapias, C. (2012). De la concesión de mares y la tronco hasta Ecopetrol. Credencial, Historia 266, http:// www.banrepcultural.org/blaavirtual/ revistas/credencial/febrero2012/ concesion-de-mares-petroleo.

- Tirado, A. (2007). Introducción a la historia económica de Colombia. Bogotá: El Ancora.

- Torres, A. (2008). Tratado de regalías mineras e hidrocarburos. Bogotá: Editorial carrea 7a Ltda.

- Vélez, F., \& Uribe, A. (1890). Código de minas colombiano, concordado y anotado. Medellín: Imprenta del departamento de Medellín. 